\title{
Shallow-to-Deep Transition of Continental Moist Convection: Cold Pools, Surface Fluxes, and Mesoscale Organization
}

\author{
MARCIN J. KUROWSKI \\ Jet Propulsion Laboratory, California Institute of Technology, Pasadena, and \\ Joint Institute for Regional Earth System Science and Engineering, Los Angeles, California \\ KAY SUSELJ \\ Jet Propulsion Laboratory, California Institute of Technology, Pasadena, California \\ WOJCIECH W. GRABOWSKI \\ National Center for Atmospheric Research, Boulder, Colorado \\ JOAO TEIXEIRA \\ Jet Propulsion Laboratory, California Institute of Technology, Pasadena, California
}

(Manuscript received 25 January 2018, in final form 13 September 2018)

\begin{abstract}
Large-eddy simulation is used to investigate the effects of cold pools driven by rain evaporation on the shallow-to-deep convection transition over land. The physically consistent methodologies are developed to obtain a time-dependent reference ensemble without cold pools and to apply interactive surface heat fluxes without modeling of surface energy and water budgets. Three different simulation ensembles are contrasted. The reference ensemble, in the spirit of one-dimensional single-column models, eliminates cold pools by horizontally homogenizing negative buoyancy production due to rain evaporation. The additional ensembles complement the reference cold-pool-free ensemble by including cold pools and by applying either interactive or prescribed surface fluxes. Contrasting these ensembles suggests possible improvements of convection parameterization in large-scale models of weather and climate. Without cold pools, the reference ensemble preserves key features of buoyancy-driven cellular convection associated with a field of convective plumes, as assumed in a typical convection parameterization. With cold pools, a significant enhancement of surface heat and moisture fluxes and about an hour delay of their daily maximum is simulated. Cold pools enhance near-surface temperature and moisture standard deviations as well as maxima of the near-surface updraft velocity. They also lead to the reduction of cloud lateral entrainment, deeper vertical development of the cloud layer, and a few-times-larger accumulated surface precipitation. Interactive surface fluxes provide a damping mechanism that noticeably suppresses all these effects. Perhaps surprisingly, cold pools do not significantly change the cloud-base convective mass flux that approximately follows the evolution of surface heat fluxes.
\end{abstract}

\section{Introduction}

Observational and numerical studies have long indicated the key role of precipitation-laden downdrafts in the formation of cold pools and a significant cold-pool impact on the surface-atmosphere exchange and on the initiation of subsequent convection (e.g., Houze and Betts 1981; Tompkins 2001; Khairoutdinov and

Corresponding author: Marcin J. Kurowski, marcin.j.kurowski@ jpl.nasa.gov
Randall 2006; Grabowski et al. 2006; Schlemmer and Hohenegger 2014; Feng et al. 2015; Torri et al. 2015). Cold-pool formation and evolution involves processes with horizontal scales from subkilometer to several tens of kilometers that can be explicitly represented by applying high-resolution large-eddy simulation (LES). However, LES is computationally demanding and is typically used only in short simulations. For contemporary large-scale weather and climate models, most of the scales resolved by LES need to be incorporated through subgrid-scale parameterizations. It follows that LES can 
be used as a reference in the development of the parameterizations that are at the heart of large-scale models. The bridge between LES and the parameterizations is defined through LES mean features that need to be properly represented by the large-scale model parameterizations. Such parameterizations have proven useful in representing large-scale effects of the boundary layer dynamics and shallow convection (e.g., Cheinet 2004; Neggers 2009; Nie and Kuang 2012; Sušelj et al. 2012, 2013). However, representing deep convection is more challenging because of a larger complexity of the processes involved. These include multiphase moist microphysics (e.g., Cotton et al. 2011) and the multiscale effects of organized deep convection that are not yet fully understood. The effects of cold pools include the deepening and widening of clouds yielding more precipitation because of a better organization of secondary convective cells forming at the edges of negatively buoyant density currents (Tompkins 2001; Khairoutdinov and Randall 2006; Schlemmer and Hohenegger 2014; Feng et al. 2015; Torri et al. 2015) and especially at their intersections (Böing et al. 2012).

A 2005 workshop on boundary layer parameterization (Teixeira et al.2008) recognized the interaction between the subcloud layer and deep convection and the physics of cold pools as a key parameterization challenge. Although important, the effects of cold pools are poorly represented in coarse-resolution global circulation models (GCMs). Redelsperger et al. (2000) proposed a simple way to parameterize the enhancement of surface fluxes in GCMs due to cold-pool activity. Grandpeix et al. (2010) developed a density current parameterization to include interactions between circular wakes (i.e., cold pools) and convection. Rio et al. (2009) showed that including a simple wake parameterization into their deep convection scheme shifts the daytime precipitation maximum into late afternoon and significantly improves the representation of the diurnal cycle of convective precipitation, one of the long-standing problems in GCMs [see Guichard et al. (2004) and references therein]. Hohenegger and Bretherton (2011) argued that the main difference between parameterizing shallow and deep convection is the need to account for precipitation. They extended their mass-flux shallow convection scheme to deep convection by modifying its three key elements: the cloud-base mass flux, the cloudbase updraft properties, and the lateral entrainment, transforming each into functions of the rain rate [see Hohenegger and Bretherton (2011) for details]. To gain more insight into the shallow-to-deep convection transition, Kuang and Bretherton (2006) contrasted PDFs of cloud properties for shallow and deep convection phases, while D'Andrea et al. (2014) extended a shallow convection scheme to simulate the timely triggering of deep convection. More complex effects, such as the development of organized convection (e.g., squall lines) still remain beyond the scope of contemporary onedimensional parameterizations.

Khairoutdinov and Randall (2006) used an LES model to study a shallow-to-deep convection transition case developed by Grabowski et al. (2006) with a prescribed evolution of surface sensible and latent heat fluxes, which mimics the daytime convective development over summertime continents. Khairoutdinov and Randall (2006) demonstrated that switching off rain evaporation in the subcloud layer suppresses the formation of cold pools. Although suppressing rain evaporation is useful in highlighting the role of evaporative cooling in the formation of cold pools and secondary circulations, doing so changes the temperature and water vapor budgets in the subcloud layer, thus affecting the surface-atmosphere coupling. The present study extends the approach used in Khairoutdinov and Randall (2006) by distributing evaporative cooling and moistening over the entire horizontal domain [as done in Böing et al. (2012)] and thus maintaining the mean nearsurface temperature and water vapor budgets. A robust evaluation of cold-pool effects requires a reference simulation without cold pools but with a physically consistent mean-subcloud-layer temperature and moisture profiles. Our approach offers an optimal framework for such an analysis. Moreover, we consider the impact of interactive surface heat fluxes on the shallow-to-deep convection transition. For that, we derive the evolving mean land surface conditions (i.e., the surface temperature and water vapor mixing ratio) that are subsequently used to run simulations with interactive surface fluxes. As a result, interactive surface flux simulations feature horizontally averaged fluxes close to those prescribed in Grabowski et al. (2006). Note that applying interactive surface fluxes is straightforward for the oceanic convection, for instance, by using a prescribed sea surface temperature. It is more cumbersome, however, for convection over land, and especially for the case of daytime shallow-to-deep convection transition considered here. The approach we use is arguably the simplest possible; in the future, a land surface scheme responding to the diurnal change of the solar insolation and soil water budget along with the surface-layer model should be considered.

Interactive surface fluxes that respond to local fluctuations of the near-surface horizontal wind, as well as the temperature and moisture fluctuations, provide a physically more consistent methodology than the prescribed fluxes of Grabowski et al. (2006) and Khairoutdinov and Randall (2006). Trier et al. (1997) showed that including 
interactive fluxes in limited-area cloud-resolving model simulations of a 22 February 1993 TOGA COARE squall line improves the results when compared to observations. In similar simulations with interactive surface fluxes targeting active monsoon and monsoon break convection near Darwin, Australia, Del Genio et al. (2012) note significant differences in the recovery of cold-pool properties to ambient conditions over the land and over the surrounding ocean. Gentine et al. (2016) discuss idealized deep convection simulations over constant sea surface temperature ocean and over a highly idealized land surface. They apply both prescribed and interactive surface fluxes and show significant differences between the impact of interactive fluxes on oceanic and land-based deep convection. Grant and van den Heever (2016) analyze the impact of interactive surface sensible heat flux on the dissipation of dry wakes as simulated by a twodimensional small-scale model. Neither of the above studies, however, focuses specifically on the shallow-todeep convection transition and how the transition and resulting deep convection is affected by the interactive surface heat fluxes. The current study fills this gap.

The paper is organized as follows. Section 2 provides details of the modeling methodology. The setup of numerical simulations is detailed in section 3. Section 4 presents the results of the simulations and quantifies the impact of cold pools on various convective properties. Besides analyzing fundamental features of the shallowto-deep convection transition in simulations with prescribed and interactive surface fluxes, we also consider statistics that can be used in improved convection parameterizations. Section 5 discusses the simulation results in the context of Monin-Obukhov similarity theory. Section 6 provides a summary and conclusions.

\section{Methodology}

To extract the impact of cold pools, we merge the LES and one-dimensional parameterization approaches by constructing two complementary datasets-one using the standard LES configuration that provides the full solution [i.e., with cold pools (CP)], and the other one with modified rain evaporation that provides the solution without cold pools (NOCP). Each of the configurations can use either time-dependent prescribed surface fluxes as in Grabowski et al. (2006) and Khairoutdinov and Randall (2006) or interactive surface fluxes (cf. Gentine et al. 2016); these will be referred to as CP_p and NOCP_p ( $p$ for prescribed fluxes) and $\mathrm{CP}_{-} \mathrm{i}$ and $\mathrm{NOCP}_{-} \mathrm{i}$ ( $\mathrm{i}$ for interactive fluxes), respectively. In addition, to increase statistical significance, we follow Grabowski (2015) and construct mini-ensembles for each configuration. The ensembles are mostly required to reduce the variability of the CP simulation results since the size of the largest resolved perturbations (i.e., cold pools) can be a significant fraction of the domain size. Each mini-ensemble consists of four independent model runs. The ensemble members differ only in realizations of the cloud field by adding a random noise of $0.5 \mathrm{~W} \mathrm{~m}^{-2}$ maximum amplitude and zero mean to the surface fluxes at each time step. Below, we describe the two main elements of the applied methodology. The first one eliminates cold pools following Böing et al. (2012) and results in the NOCP_i mini-ensemble. The second one allows incorporation of interactive fluxes into the setup of Grabowski et al. (2006) resulting in the CP_i mini-ensemble.

\section{a. Mimicking $1 D$ rain evaporation in LES}

To represent one-dimensional (1D) rain evaporation effects in LES, we allow for the local rain evaporation, but the contribution from this process only affects mean (1D) temperature and moisture profiles as in Böing et al. (2012). It follows that precipitation still forms within and falls out from individual clouds, and rain is subject to local evaporation. However, local evaporation sources of the temperature and moisture are averaged horizontally and redistributed over all model columns at a given height, as in 1D models. For a simulation with prescribed surface fluxes and rain evaporation switched off completely below the cloud base (i.e., as in Khairoutdinov and Randall 2006), the surface layer after $10 \mathrm{~h}$ becomes around $2 \mathrm{~K}$ warmer and $1.5 \mathrm{~g} \mathrm{~kg}^{-1}$ drier than in simulations with rain evaporation (not shown). These differences are the net contribution from the evaporative cooling and moistening that is accounted for in NOCP_i with $1 \mathrm{D}$ rain evaporation.

Local buoyancy, the main driver for vertical motions, can be expressed by the density potential temperature fluctuations as

$$
\theta_{d}^{\prime}=\theta^{\prime}\left(1+0.608 q_{v}^{\prime}-q_{l}\right),
$$

where $q_{l}$ combines all condensed water species (including ice and liquid phases), and primes denote deviations from the hydrostatically balanced reference state. Since rain evaporation produces negative buoyancy, ${ }^{1}$ its accumulated effects trigger downdrafts responsible for subsequent cold-pool formations. In the modified approach, this source of buoyancy is removed from Eq. (1), but its mean thermodynamic effects such as cooling and moistening of the subcloud layer are still

\footnotetext{
${ }^{1}$ Rain evaporation also reduces the mass of rainwater in $q_{l}$, which produces positive buoyancy perturbations. However, evaporative cooling exceeds the weight decrease by at least an order of magnitude.
} 
present, unlike in Khairoutdinov and Randall (2006). Therefore, local sources of $\theta$ and $q_{v}$ are not removed but homogenized in the horizontal.

\section{b. Interactive surface fluxes}

Transition from the prescribed to interactive surface heat fluxes is generally more complex than from interactive to prescribed fluxes because the latter simply involves horizontal averaging of the surface flux values. Moreover, the transition requires additional assumptions regarding the land surface properties and, in our case, the elimination of cold-pool effects. Surface potential temperature and water vapor fluxes $F$ are approximated by the bulk aerodynamic formula

$$
F_{a}=C_{a}\left|u_{0}\right|\left(a_{s}-a_{0}\right)
$$

where $a=\left\{\theta, q_{v}\right\}, C_{a}$ is the bulk transfer coefficient for either heat or moisture, $\left|u_{0}\right|$ is the magnitude of the nearsurface horizontal wind, and the subscripts 0 and $s$ refer to the values at the lowest model level and the underlying surface, respectively. Although transfer coefficients generally depend on stability and flow velocity (e.g., Mahrt et al. 2001; Wallace and Hobbs 2006), we assume a fixed value of $C_{a}$, the same for both variables, to facilitate the simplest possible transition from prescribed to interactive fluxes for the LBA case (see section 3 for more details). To find the land surface temperature and moisture evolutions, we first run an ensemble of three simulations driven by the prescribed surface fluxes using the NOCP_p configuration. The simulated ensemble-mean time series of the horizontally averaged atmospheric temperature, water vapor mixing ratio, and horizontal velocity at the lowest model level from NOCP_p are subsequently used to calculate the required land surface conditions from Eq. (2) with the left-hand side from Grabowski et al. (2006). These timedependent surface temperature and moisture conditions are subsequently used to derive interactive surface fluxes in the NOCP_i and $\mathrm{CP}_{-} \mathrm{i}$ mini-ensembles.

The above approximations allow substituting, in a simple way, the prescribed fluxes from Grabowski et al. (2006) and Khairoutdinov and Randall (2006) with the ones that interact with the surface, yet on average are close to observationally based values. A more comprehensive approach to the surface layer would require using the Monin-Obukhov similarity theory to find the transfer coefficients, which increases the complexity of the problem and raises additional questions regarding the accuracy of such an approach. In similarity theory, turbulent transfer coefficients are derived assuming the existence of an equilibrium state unaffected by outer scales. For deep convection, these outer scales can strongly interfere with the surface layer through cold pools (Gentine et al. 2016), disturbing the quasiequilibrium state and homogeneous assumption of the surface-layer turbulence.

\section{The model and model simulations}

The numerical model employed in this study is the Advanced Research WRF model suitable for simulating high-resolution three-dimensional moist atmospheric flows (Skamarock et al. 2008). The computational domain extends over $70 \mathrm{~km} \times 70 \mathrm{~km} \times 21 \mathrm{~km}$. The horizontal grid length is fixed at $100 \mathrm{~m}$, while the vertical grid length increases from around $60 \mathrm{~m}$ near the ground to around $350 \mathrm{~m}$ near the domain top. Periodic lateral boundary conditions are applied. A sponge layer extends above $17 \mathrm{~km}$ to prevent reflections of gravity waves from the domain top. Initial profiles of the temperature, moisture, and horizontal wind are the same as in Grabowski et al. (2006). A 1.5-order closure based on a prognostic equation for turbulent kinetic energy is used to represent the subgrid-scale transport. Cloud microphysical processes are represented with the Lin et al. (1983) scheme that employs six different classes of water: vapor, cloud liquid, cloud ice, graupel, snow, and rain. Mixing ratios for these variables are included in the set of model prognostic variables. Surface transfer coefficients (see the previous section) are prescribed at 0.018. Other values of $C_{a}$ (i.e., 0.012 and 0.030 ) have also been tested, but the conclusions remain consistent with those obtained for the basic value. Note that for the increased (decreased) $C_{a}$, the derived land surface temperature and moisture have to decrease (increase) to maintain the same values of the surface fluxes. We extend the original integration time in Grabowski et al. (2006) from 6 to $10 \mathrm{~h}$ to better expose the effects of cold pools that develop in the second part of the day, after the transition to the deep convection regime. We also neglect the small prescribed time-dependent radiative forcings [only available for the first $6 \mathrm{~h}$ in the Grabowski et al. (2006) setup] following Khairoutdinov and Randall (2006) and Grabowski (2015). For the postprocessing, the output data are saved every $5 \mathrm{~min}$.

Using the calculated land surface temperature and moisture evolutions (section $2 b$ ), we first construct a reference mini-ensemble for NOCP_i configuration with interactive surface fluxes. Next, we run a miniensemble with interactive fluxes featuring cold pools that affect both convection organization and surface exchange. These simulations are referred to as $\mathrm{CP}$ _i. Finally, we run a mini-ensemble of LES with prescribed surface fluxes as in Grabowski et al. (2006), where cold pools only affect convection organization and do not 
TABLE 1. List of main simulations carried out in the study. NOCP_p is used to derive land surface conditions used by the interactive-flux simulations.

\begin{tabular}{lclc}
\hline \hline $\begin{array}{c}\text { Simulation } \\
\text { name }\end{array}$ & $\begin{array}{c}\text { Rain evaporation } \\
\text { effects }\end{array}$ & \multicolumn{1}{c}{ Surface fluxes } & $\begin{array}{c}\text { Cold } \\
\text { pools }\end{array}$ \\
\hline NOCP_p & 1D & $\begin{array}{c}\text { Prescribed from } \\
\text { Grabowski et al. (2006) }\end{array}$ & No \\
NOCP_i & 1D & $\begin{array}{l}\text { Interactive } \\
\text { Interactive }\end{array}$ & No \\
CP_i & 3D & Prescribed from CP_i & Yes \\
CP_p & 3D & Yes \\
\hline
\end{tabular}

interact with the surface; hereafter $\mathrm{CP}_{-}$p. All experiments are summarized in Table 1 . Convection is primarily driven by the diurnal evolution of the surface fluxes with the Bowen ratio of around 0.5 (typical for a tropical forest), upon the presence of a weak shear. Notice that the simulated convection development over land starts from dry convection (0-1 h) that gradually transitions to moist shallow convection $(2-4 \mathrm{~h})$ and then to more strongly precipitating deep convection (cf. Khairoutdinov and Randall 2006).

\section{Results}

The simulation results are first analyzed for the subcloud layer (directly impacted by cold pools) and then for the cloud layer (indirectly impacted by cold pools, being also the layer of their origin). A special emphasis is put on evaluating the reference NOCP_i solution that has never been used in this context before.

\section{a. Near-surface buoyancy}

Figure 1 shows horizontal cross sections of the virtual potential temperature at the lowest model level for NOCP_i and $\mathrm{CP}_{-} \mathrm{i}$ from randomly selected ensemble members after 4 and $8 \mathrm{~h}$ (i.e., for shallow and deep convection, respectively). The early convection development is typical of unstable layers heated from below as it takes the form of cellular structures edged by a positively buoyant upwelling air (e.g., Mason 1989; van Heerwaarden and Mellado 2016). Their width ranges from several hundred meters up to several kilometers, with the most common sizes around $1 \mathrm{~km}$. The cellular structure remains dominant throughout the NOCP_i simulation, while for $\mathrm{CP}_{-} \mathrm{i}$, it can transition into largerscale forms because of the presence of cold pools (see section 4b). Note that convective cells are still present for $\mathrm{CP}_{-} \mathrm{i}$ in the areas unaffected by cold pools, with strongly deformed shapes close to the cold-pool edges.

The near-surface buoyancy is responsible for the structure of vertical velocity aloft (Fig. 2). Convective updrafts simulated by NOCP_i undergo gradual dilution with height and only the strongest and least diluted ones reach the condensation level. As a result, NOCP_i shows a relatively uniform spatial distribution of cloud water associated with weakly interacting narrow plumes at hour 4 and 8 . Mean horizontal distance between the cloud formations is on the order of $1 \mathrm{~km}$, as is the mean size of the underlying cells, which is close to the depth of the well-mixed subcloud layer. The results for NOCP_i are similar to those for the buoyancy-driven planetary boundary layer, for which eddies exhibit polygonal spoke patterns near the surface and evolve into isolated updrafts aloft (Mason 1989; Moeng and Sullivan 1994). Also, the simulated NOCP_i convection resembles what is typically assumed in parameterizations about the ensemble of convective plumes, without accounting for the effects of cold pools.

For $\mathrm{CP}_{-} \mathrm{i}$, the shallow convection stage is the same as for NOCP_i. As cold pools develop and spread over the surface, they suppress the small-scale cellular convection and enhance clustering of the near-surface buoyancy. They can also enhance mechanical lifting of the air at their edges (section 4d). As a result, notable changes in the cloud layer are also observed (Fig. 2; see also sections $4 \mathrm{e}-4 \mathrm{~h}$ ).

\section{b. Cold-pool strength}

To identify cold pools that are the driving factor for the observed differences, we use a simple algorithm detecting the regions of negative buoyancy, while minimizing the impact of small-scale features associated with cellular convection (see the appendix). The strength of cold pools $C$ is then calculated using (Rotunno et al. 1988)

$$
C^{2}=-2 g \int_{0}^{H} \frac{\bar{\theta}_{v, \mathrm{cp}}-\bar{\theta}_{v, \mathrm{env}}}{\bar{\theta}_{v, \mathrm{env}}} d z,
$$

where $g$ is gravitational acceleration, $H$ typically denotes the height at which buoyancy becomes zero, $\overline{\theta_{v}}$ is the horizontally averaged virtual potential temperature, and the subscripts "cp" and "env" relate to the cold-pool region and the remaining environment, respectively. Since the LES buoyancy reveals a significant small-scale variability, we choose $H$ to be the cloud-base height. Therefore, $C$ is an integral measure of the subcloud negative buoyancy within cold pools that can be, under certain conditions, associated with the maximum propagation speed of a gust front (Rotunno et al. 1988). Additionally, we also analyze the relative cold-pool strength, which is simply $C a$, where $a$ is the fractional area of all cold pools. The area-weighted metric can be interpreted as a large-scale measure of the total cold-pool intensity.

Figure 3 shows time series of the cold-pool number per $(100 \mathrm{~km})^{2}$, mean fractional area, mean strength, and 

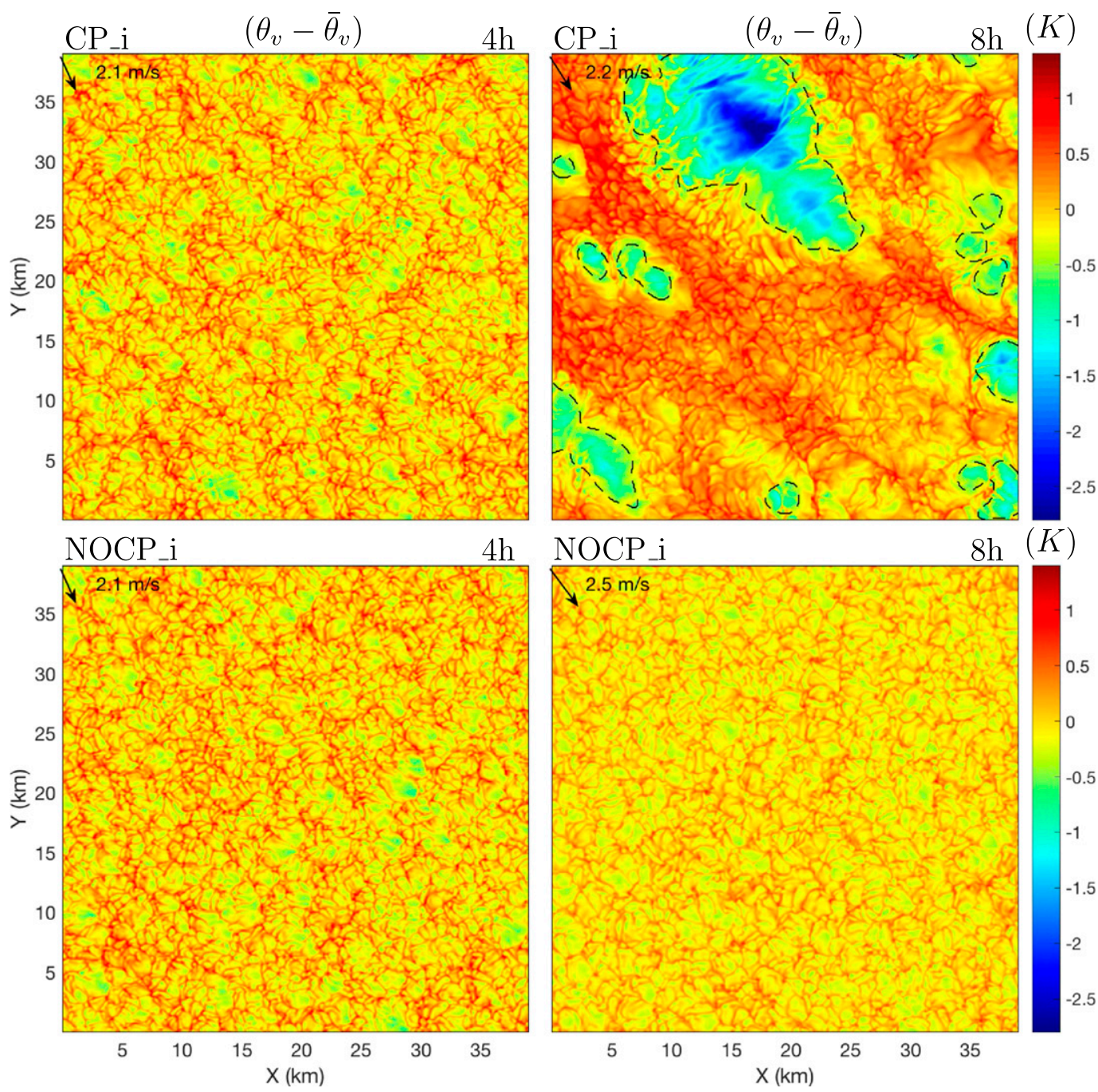

FIG. 1. Virtual potential temperature (K) at the lowest model level after (left) 4 and (left) $8 \mathrm{~h}$ for randomly selected members of the (top) $\mathrm{CP}_{\_} \mathrm{i}$ and (bottom) NOCP_i ensembles. Only a quarter of the domain is shown. Contours of cold pools are marked with black dashed lines.

mean area-weighted strength, from the LES ensembles. Two phases of the cold-pool development can be distinguished based on the CP solutions. Cold-pool number first reaches a maximum of $25-30(100 \mathrm{~km})^{-2}$ at about hour 6 and then it slowly declines during the next $4 \mathrm{~h}$. Concomitantly, the mean area also grows during the first phase and then either notably decreases the growth rate (for $\mathrm{CP} \_$p) or saturates (for $\mathrm{CP} \_\mathrm{i}$ ), with a hint of decay in the last hour. Cold-pool strength tends to slowly grow until hour 9 , remaining on average around $5 \mathrm{~m} \mathrm{~s}^{-1}$. The product of cumulative area and strength has a clear signal that is approximately constant for $\mathrm{CP} \_\mathrm{i}$ between 6 and $9 \mathrm{~h}$, while slowly increasing for $\mathrm{CP}_{-} \mathrm{p}$ during that time. Using interactive fluxes yields on average five to eight more cold pools that are up to 2 times smaller than for prescribed fluxes, consistent with the results of
Gentine et al. (2016). A physical mechanism controlling the differences between the $\mathrm{CP}_{-} \mathrm{i}$ and $\mathrm{CP}_{-} \mathrm{p}$ solutions is explained in section $4 \mathrm{~d}$.

\section{c. Surface fluxes}

Figures 4 and 5 illustrate spatial distributions of interactive sensible and latent heat surface fluxes after 4 and $8 \mathrm{~h}$ from NOCP_i and $\mathrm{CP}$ i. The small-scale cellular structures associated with convective cells from Fig. 1 are similar for both simulations at hour 4 . At hour 8, their general structure remains unchanged for NOCP_i, while for $\mathrm{CP}_{-} \mathrm{i}$, surface fluxes experience strong local enhancements or suppressions depending on the stage of the cold-pool development. In particular, the simulated maxima for $\mathrm{CP}$ i f found within the most active cold pools can exceed those for NOCP_i by a factor of 2 . The $\mathrm{CP} \_\mathrm{i}$ 

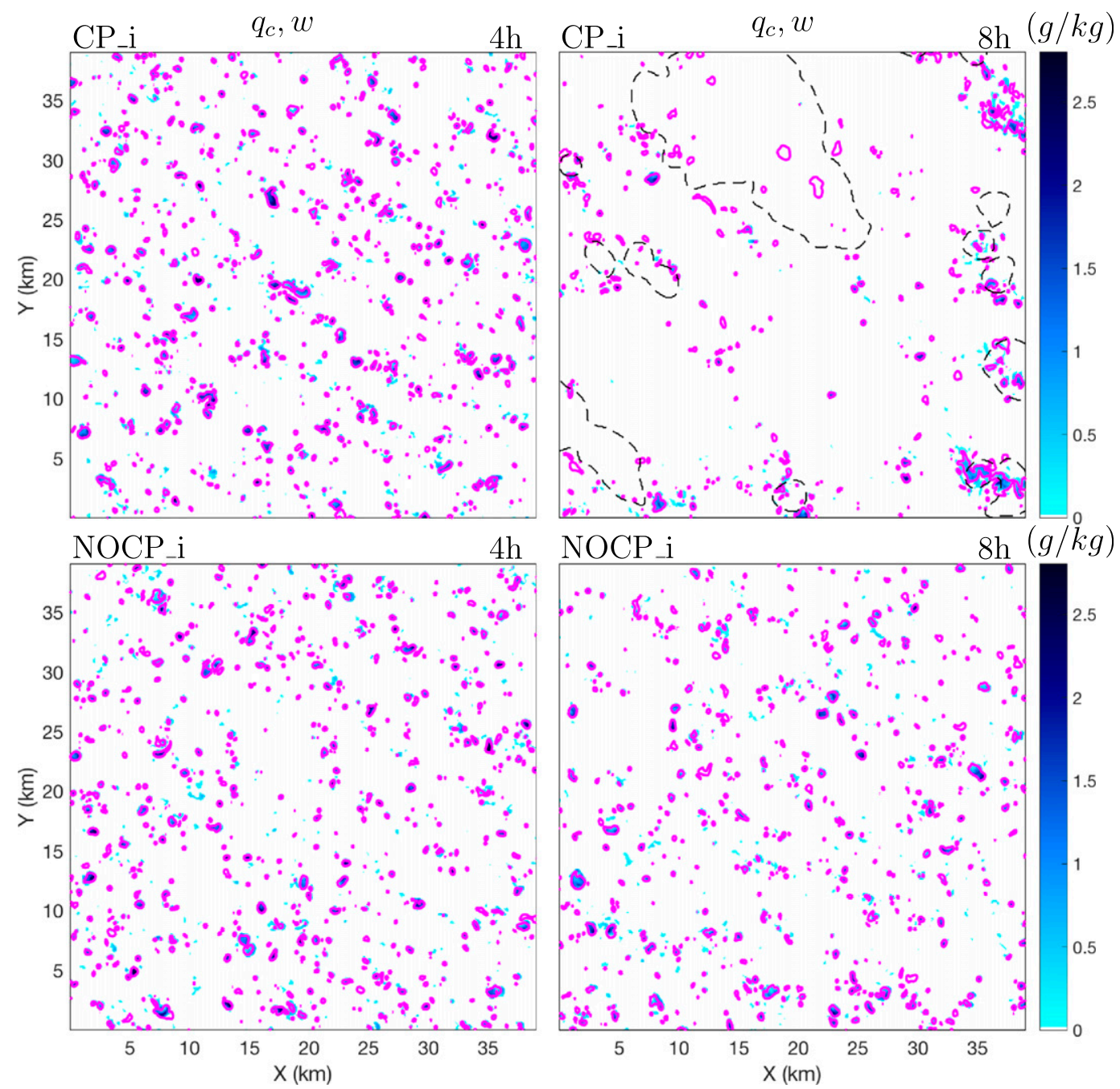

FIG. 2. Cloud water mixing ratio ( $\mathrm{g} \mathrm{kg}^{-1}$; blue shading) and vertical velocity (for $1 \mathrm{~m} \mathrm{~s}^{-1}$; contours) at $2 \mathrm{~km}$ after (left) 4 and (right) $8 \mathrm{~h}$ for the same members of (top) $\mathrm{CP}_{-} \mathrm{i}$ and (bottom) NOCP_i ensembles as in Fig. 1. The same quarters of the domain as in Fig. 1 are shown. Contours of cold pools are marked with black dashed lines.

fluxes are also more clustered; that is, the regions of enhanced (or suppressed) values are much larger and depend on the size of cold pools.

Figure 6 documents evolutions of the mean sensible and latent heat surface fluxes from $\mathrm{NOCP}_{-} \mathrm{i}$ and $\mathrm{CP}_{-} \mathrm{i}$. The interactive fluxes from NOCP_i are similar to the idealized fluxes from Grabowski et al. (2006). This implies that the coupling between land and atmosphere does not significantly change the near-surface atmospheric conditions for the buoyancy-driven convection void of cold pools (omitting the nonlinearity of stability corrections). With cold pools, the mean fluxes in $\mathrm{CP}_{-} \mathrm{i}$ exceed those in NOCP_i after hour 5 by as much as several tens of watts per square meter and with comparable values for the latent and sensible fluxes. The time-integrated contributions from cold pools add around $4 \%$ to the surface moisture source and about $10 \%$ to the surface heat source (thus providing more moisture and energy into the atmosphere). The largest enhancement occurs around one hour after the NOCP_i's diurnal maximum. Consequently, the daily maximum is not only notably larger for $\mathrm{CP}_{-} \mathrm{i}$ but is also delayed by approximately $1 \mathrm{~h}$. The delay is associated with a complex response of the system: First, cold pools enhance the circulation, which leads to stronger precipitation (section 4e), which later strengthens the cold-pool formation. For the fluxes, the cycle apparently maximizes after a few eddy turnover times, where eddy turnover time can be defined as $\tau=z_{t} / w_{*}$, with $z_{t}$ denoting the top of the cloud layer and $w_{*}$ depicting the convective velocity scale (see section 5) calculated for $z_{t}$ as the vertical scale. In the analyzed case, the eddy turnover time is 


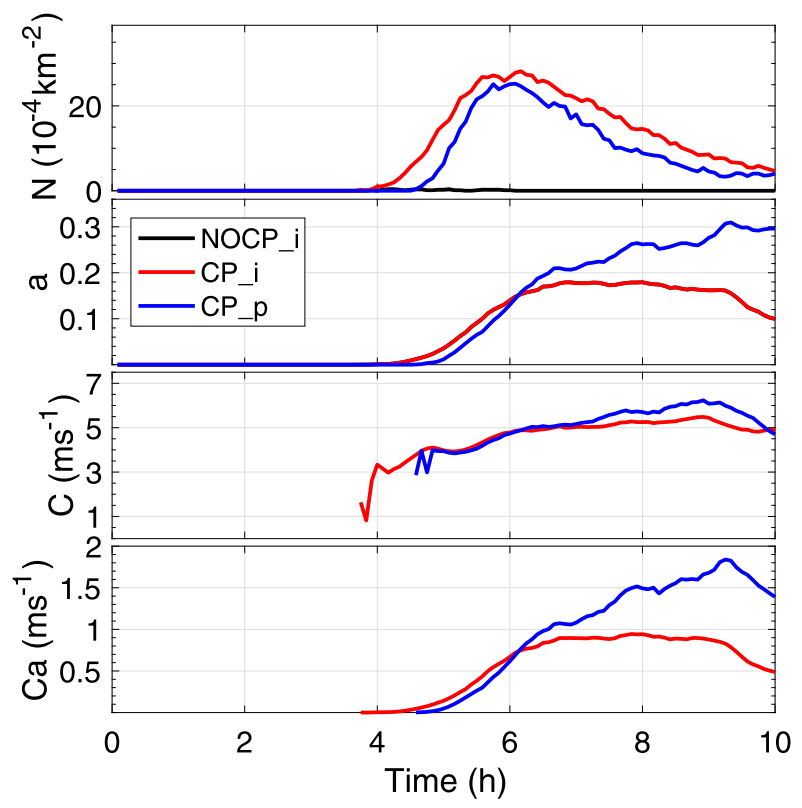

FIG. 3. Domain-averaged statistics of cold pools from the LES ensembles (as listed in the legend) for (top)- (bottom): cold-pool number $N\left[(100 \mathrm{~km})^{-2}\right]$, cumulative fractional area $a$, intensity $C$, and area-weighted intensity $\mathrm{Ca}$.

around $20-30 \mathrm{~min}$, which agrees well with the observationally obtained time scale characterizing the life cycle of deep convective cells (Byers and Braham 1949). At the end of the day, the $\mathrm{CP}_{-} \mathrm{i}$ fluxes converge to the NOCP_i fluxes. Further investigation would be needed to determine which factors control the timing of the enhancement. Also, one can expect that the enhancement would be smaller for a simulation with the land surface model substituting the prescribed land surface conditions owing to the low thermal inertia of land surface (i.e., limited heat and moisture capacity; Del Genio et al. 2012).

Sensitivity tests with either smaller or larger drag coefficients (viz. 0.012 and 0.03 ) yield similar increases of the fluxes $\left(\mathrm{W} \mathrm{m}^{-2}\right)$ as long as the corresponding land surface conditions satisfy Eq. (2) (not shown). In other words, the results only slightly depend on the drag coefficient given the prescribed reference evolution of mean surface fluxes. The low sensitivity to the drag coefficient suggests that the effects of cold pools should be similar for a variety of land types characterized by similar surface fluxes. However, different land types are usually associated with different diurnal cycles of the surface fluxes and, perhaps more importantly, with different partitioning between sensible and latent heat fluxes (i.e., the Bowen ratio; see Thomas et al. 2018) and with different environmental conditions that strongly determine the strength of cold pools (Schlemmer and Hohenegger 2014).
Additional analysis to evaluate the relative importance of wind gustiness and temperature/moisture perturbations on the surface fluxes were performed but are not included in the paper due to limited space. Although one may generally expect the strongest wind gustiness to occur at the cold-pool edges (Drager and van den Heever 2017), this is not always the case as seen in the wide regions of enhanced surface fluxes in Figs. 4 and 5 around $X=10-20 \mathrm{~km}$ and $Y=30-35 \mathrm{~km}$ that are associated with the larger values of wind magnitude. Moreover, correlation coefficients between the wind magnitude and the fluxes are close to 1 when cold pools are not present (i.e., at $4 \mathrm{~h}$ or at $8 \mathrm{~h}$ for NOCP_i), and decrease to around 0.9 when they are included (i.e., at $8 \mathrm{~h}$ for $\left.\mathrm{CP} \_\mathrm{i}\right)$. At the same time, coefficients between the thermodynamic perturbations and the fluxes change from $0-0.2$ to $0.4-0.5$ indicating a weak but increasing dependence. Complementary simulations for interactive fluxes applying homogenized temperature and moisture along with local wind (i.e., including horizontal wind variability) give almost the same enhancement of mean surface fluxes as for $\mathrm{CP}$ i.

The surface flux distributions unaffected by cold pools are nearly Gaussian, with the standard deviations closely following the evolutions of surface fluxes (not shown). Standard deviations of the heat and moisture fluxes reach values as high as 90 and $220 \mathrm{~W} \mathrm{~m}^{-2}$ around local noon, approximately scaling with the Bowen ratio. Cold pools enhance standard deviations by an additional $50-60 \mathrm{~W} \mathrm{~m}^{-2}$ at most (around from 5 to $6 \mathrm{~h}$ ) for both fluxes, with the contributions decreasing to around $20 \mathrm{~W} \mathrm{~m}^{-2}$ at $10 \mathrm{~h}$. The skewness of the two distributions grows from 0.1 to 0.3 (typical for $N O C P \_i$ ) to around 1 at $8 \mathrm{~h}$ and a few times more at $10 \mathrm{~h}$, when the ensemble means approach zero.

\section{d. Near-surface atmospheric conditions}

Assessing variability of the near-surface temperature, moisture, and vertical velocity is important from the parameterization point of view as it can be used to determine the updraft properties at the surface (cf. Cheinet 2004). Figure 7 shows the time series of the horizontally averaged water vapor mixing ratio, temperature, and magnitude of horizontal wind at the lowest model level (i.e., at around $33 \mathrm{~m}$ ) from NOCP_i, CP_i, and CP_p. For CP_p, the near-surface conditions are only affected by the overall dynamics (e.g., cloud-scale and mesoscale downdrafts). For NOCP_i and $\mathrm{CP} \_\mathrm{i}$, the near-surface conditions are additionally affected by the land-atmosphere coupling (i.e., the surface fluxes and their distribution). The fastest changes (approximately $1 \mathrm{~K} \mathrm{~h}^{-1}$ and $-0.25 \mathrm{~g} \mathrm{~kg}^{-1} \mathrm{~h}^{-1}$ ) occur between hour 3 and hour 5. Differences between the three ensembles are 

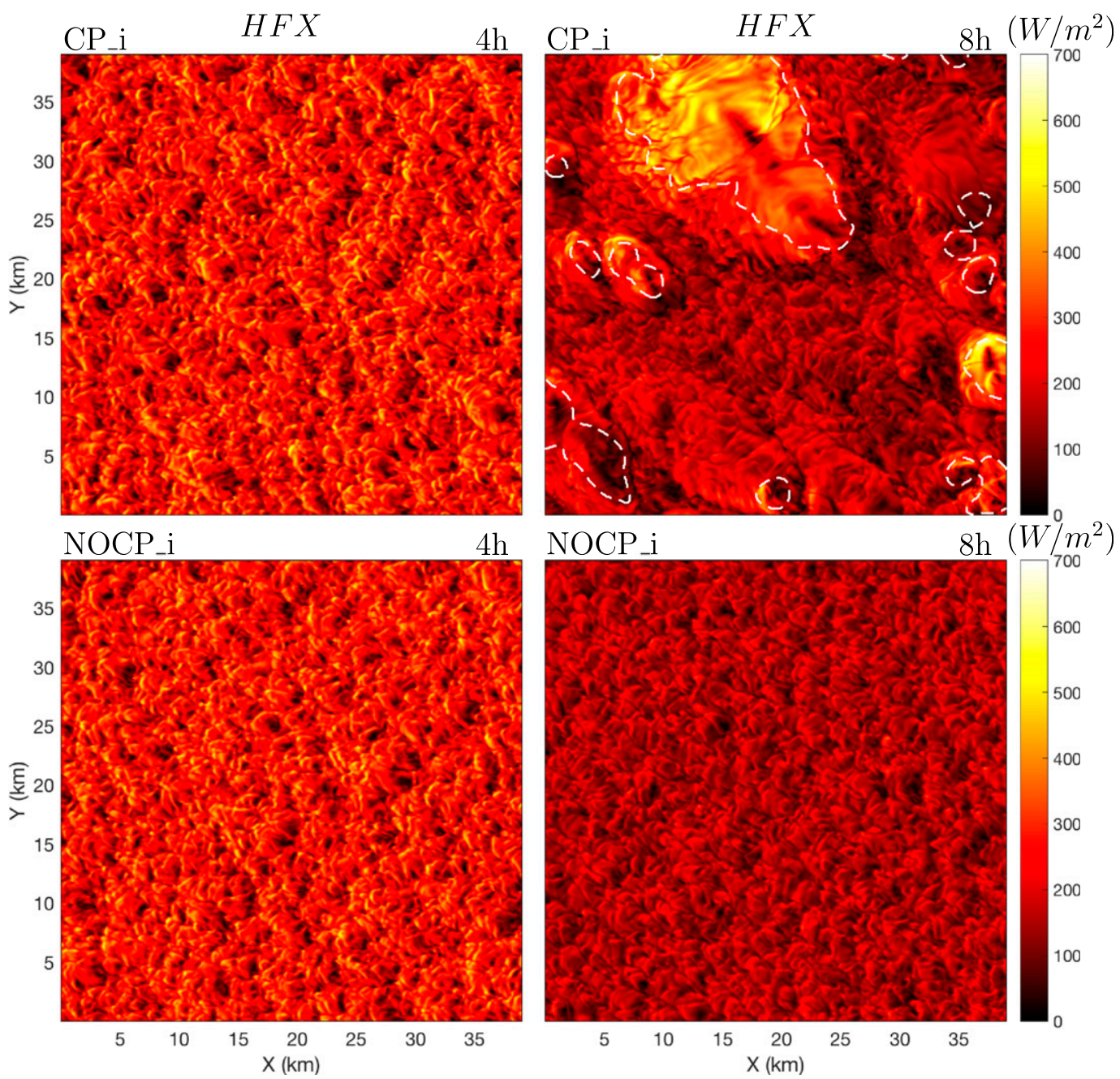

FIG. 4. Surface sensible heat flux after (left) 4 and (right) $8 \mathrm{~h}$ for the same members of (top) CP_i and (bottom) NOCP_i ensembles as in Figs. 1 and 2. The same quarters of the domain as in Figs. 1 and 2 are shown. Contours of cold pools are marked with white dashed lines.

small until hour 6 and arguably more significant after that. The prescribed-fluxes ensemble CP_p shows the largest differences from NOCP_i, reaching as much as $-1 \mathrm{~K}$ and $0.8 \mathrm{~g} \mathrm{~kg}^{-1}$ at the end of the simulation. Moreover, the final differences between NOCP_i and $\mathrm{CP}_{-} \mathrm{i}$ are smaller than between $\mathrm{CP}_{-} \mathrm{i}$ and $\mathrm{CP}_{-} \mathrm{p}$. As mentioned in section 2 , for a test simulation with rain evaporation switched off below cloud base (as in Khairoutdinov and Randall 2006), and based on prescribed fluxes, the surface layer after $10 \mathrm{~h}$ becomes around $2 \mathrm{~K}$ warmer and $1.5 \mathrm{~g} \mathrm{~kg}^{-1}$ drier than for NOCP_i. The increase in the magnitude of horizontal velocity is comparable for both $\mathrm{CP}_{-} \mathrm{i}$ and $\mathrm{CP} \_$p, with the largest enhancement occurring around hour 7 , in correlation with the enhancement of surface fluxes. Note that the cold-pool-induced enhancement decreases in the last $3 \mathrm{~h}$, contrary to the domain-averaged cold-pool strength
(Fig. 3). This suggests that, when cold pools become too large, their wind gustiness around the edges merely balances the weakening of winds away from the edges.

Figure 8 shows the corresponding standard deviations of the water vapor mixing ratio and temperature and additionally of vertical velocity, ${ }^{2}$ for the three ensembles. For NOCP_i, standard deviations follow the evolutions of surface fluxes: After the spinup, they smoothly grow in the morning and decrease in the afternoon at a similar rate. Maximum values are around $0.25 \mathrm{~g} \mathrm{~kg}^{-1}, 0.25 \mathrm{~K}$, and $0.75 \mathrm{~m} \mathrm{~s}^{-1}$. This dependence to surface fluxes resembles the surface-layer scalings based on the Monin-Obukhov

\footnotetext{
${ }^{2}$ Vertical velocity is taken at the second model level since it diminishes at the first model level.
} 

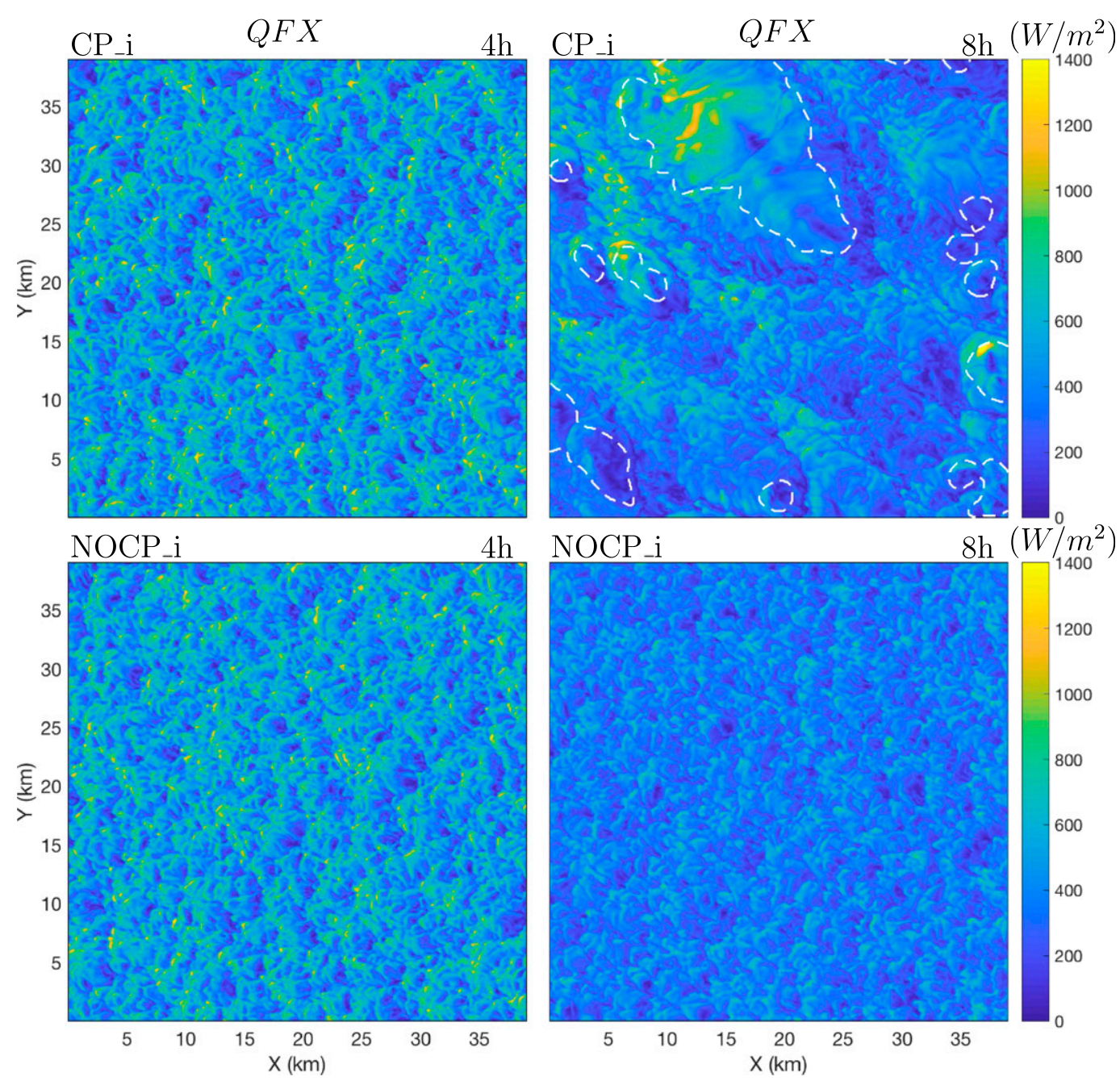

FIG. 5. As in Fig. 3, but for the surface latent heat flux.

similarity theory for the convective boundary layer; we discuss this in more detail in section 5.

For CP_p and CP_i, standard deviations of the temperature and moisture strongly increase after the hour 5 . The enhancements of moisture and temperature tend to saturate for $\mathrm{CP}$ i at $0.25 \mathrm{~g} \mathrm{~kg}^{-1}$ and $0.3 \mathrm{~K}$, respectively. For CP_p, they almost steadily increase until the end of the simulation. Both enhancements correlate well with the evolutions of cold-pool strength (Fig. 3). The difference between $\mathrm{CP}_{-} \mathrm{i}$ and $\mathrm{NOCP}_{-} \mathrm{i}$ is due to the presence of cold pools, whereas the difference between $\mathrm{CP} \_\mathrm{p}$ and $\mathrm{CP}_{-} \mathrm{i}$ is likely due to a damping mechanism that operates for interactive fluxes. A schematic explanation of the mechanism is shown in Fig. 9. Interactive surface temperature and moisture fluxes depend on the amplitude of near-surface temperature and moisture perturbations. With uniform surface conditions, cooler and drier regions are subject to larger surface fluxes and thus larger heating and moistening. As a result, near-surface temperature and moisture perturbations are damped. In contrast, prescribed surface fluxes simply shift the nearsurface temperature and moisture fields without affecting their standard deviations. Therefore, the simulated increase for $\mathrm{CP}_{-} \mathrm{p}$ is exclusively a measure of the impact from cold pools not smoothed out by interactive fluxes, similar to Gentine et al. (2016) and Grant and van den Heever (2016).

Contrary to the thermodynamic fields, vertical velocity variance is only weakly affected by the presence of cold pools. Moreover, the induced changes are of the opposite sign, since $\sigma_{w}$ decreases for the CP simulations. To understand these changes, Fig. 10 shows normalized PDFs of vertical velocity at $4,6,8$, and $10 \mathrm{~h}$. We first note that all the distributions are not perfectly Gaussian. In fact, they are better described by a double Gaussian than a single Gaussian distribution: Root-mean-square 


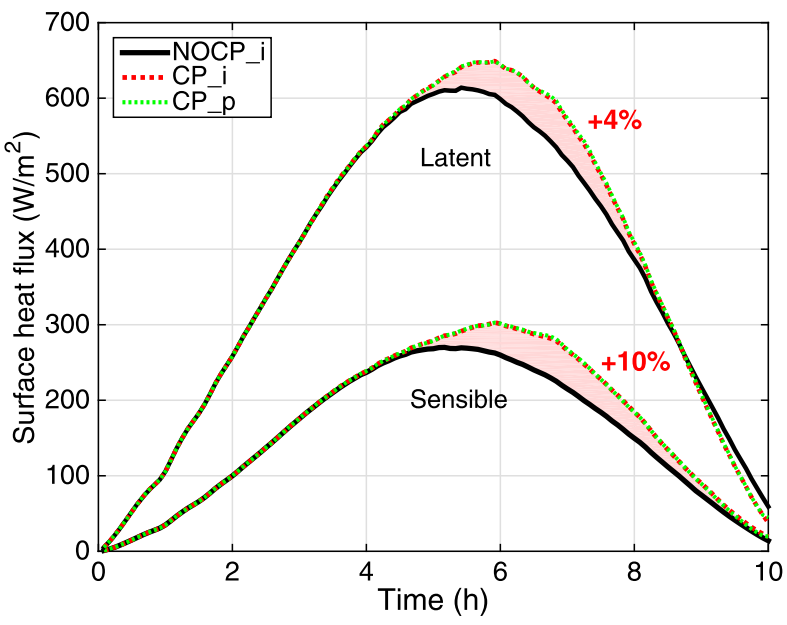

FIG. 6. Time series of the interactive surface latent and sensible heat fluxes for $\mathrm{NOCP}_{-} \mathrm{i}$ and $\mathrm{CP}_{-} \mathrm{i}$. The horizontally averaged values from $\mathrm{CP} \_\mathrm{i}$ are also used by $\mathrm{CP} \_\mathrm{p}$. The enhancement of surface fluxes due to cold pools is shaded red. Time integrals $\left(\mathrm{J} \mathrm{m}^{-2}\right)$ of the differences between LES and NOCP_i are comparable for both fluxes, and their relative increases are $4 \%$ and $10 \%$ for the latent and sensible heats, respectively. The results represent the ensemble means.

errors between the fitted functions and the LES results integrated over the normalized PDFs are 0.005 and 0.04 (remaining almost constant between 3 and $10 \mathrm{~h}$ ), respectively. The weak bimodality (i.e., with only one local maximum and a small positive skewness of $0.3-0.4$ ) is associated with the buoyancy-driven cellular convection, for which narrower yet stronger updrafts contribute to the positive part of the distribution, while weaker and wider areas of subsiding air form the negative part. For NOCP_i, this bimodality is apparent for most of the time, with the spread of the distribution clearly depending on the magnitude of surface fluxes. Cold pools suppress the cellular convection (cf. Fig. 1), as seen by the narrowing of the two Gaussians (both for positive and negative velocities) and shifting them toward zero. In other words, when convective cells diminish under the impact of cold pools, the frequency of occurrence of the near-zero velocities increases.

Along with narrowing the spread of the PDFs, cold pools widen their tails. For instance, maximum vertical velocity $w_{\max }$ increases near the surface by $0.5-1 \mathrm{~m} \mathrm{~s}^{-1}$, as shown in Fig. 11 (this increase is not seen in Fig. 10 because of a linear vertical scale used). A similar change is also simulated for the left tail, with typically $20 \%-$ $30 \%$ larger values compared to the right tail (not shown). Since the ensemble $w_{\max }$ is noisy, we also plot mean vertical velocity for $0.1 \%$ of the right tails of the PDFs $w_{0.1 \%}$ (including around 480 grid points), which increases by around $0.2 \mathrm{~m} \mathrm{~s}^{-1}$. The enhancement can be interpreted as an additional mechanical impact of the

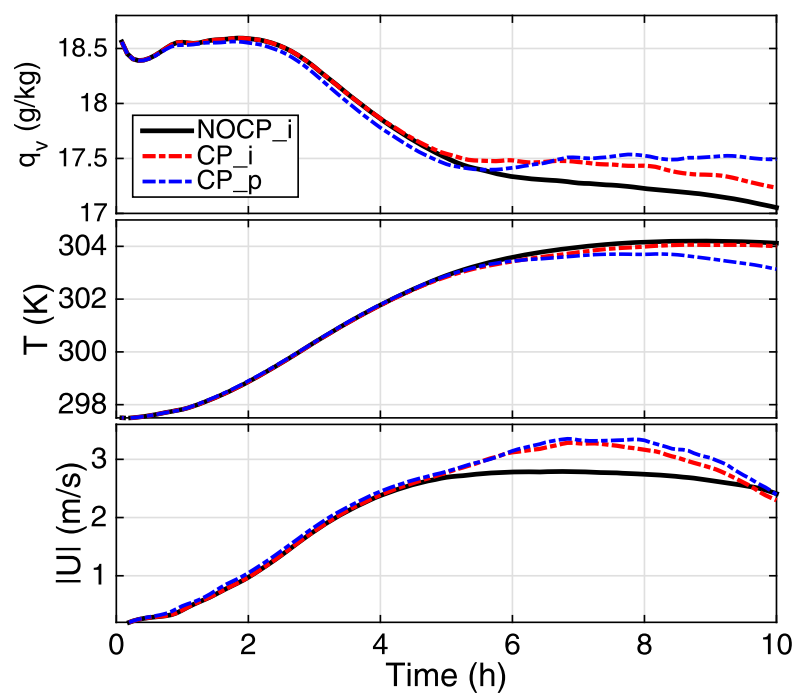

FIG. 7. Time series of the ensemble-averaged (top) water vapor mixing ratio, (middle) mean temperature, and (bottom) wind magnitude at the lowest model level.

horizontal wind convergence, as any potential differences in the buoyancy at the lowest model levels have a limited impact on the vertical velocity of a rising air. Differences in the vertical velocity increase to $2-3 \mathrm{~m} \mathrm{~s}^{-1}$ at the cloud base for $w_{\max }$ and to around $1 \mathrm{~m} \mathrm{~s}^{-1}$ for $w_{0.1 \%}$. The maximum vertical velocity tends to be $0.1-0.2 \mathrm{~m} \mathrm{~s}^{-1}$ smaller for $\mathrm{CP} \_\mathrm{p}$ (blue line) than for $\mathrm{CP} \_\mathrm{i}$ (red line) in the first $6 \mathrm{~h}$, especially near the surface. The relation reverses at a more mature stage of deep convection, mostly just below cloud base, where $\mathrm{CP}$ p values can reach as much as $1.5 \mathrm{~m} \mathrm{~s}^{-1}$ more than for $\mathrm{CP}_{-} \mathrm{i}$. These differences are also seen for $w_{0.1} \%$, reaching $0.5-0.6 \mathrm{~m} \mathrm{~s}^{-1}$.

Since the vertical velocity tends to grow more strongly for $\mathrm{CP}_{-} \mathrm{p}$ between the surface layer and the cloud base, one possible explanation is that the CP_p updrafts become stronger owing to a larger accumulation of the near-surface buoyancy, which for $\mathrm{CP}_{-} \mathrm{i}$ is suppressed by interactive fluxes. Indeed, the maxima of positive temperature and moisture perturbations (Fig. 12) for $\mathrm{CP}_{-} \mathrm{p}$ and $\mathrm{CP}_{-} \mathrm{i}$ are larger than those for NOCP_i. Similar to the near-surface standard deviations from Fig. 8, they saturate for $\mathrm{CP}_{-} \mathrm{i}$ (at 0.8 $0.9 \mathrm{~g} \mathrm{~kg}^{-1}$ and $0.5 \mathrm{~K}$ ) and keep increasing for $\mathrm{CP}_{-} \mathrm{p}$, again in correlation with the evolution of mean coldpool strength. These differences translate into larger skewness for $C_{-} \_p$ than for $C_{-}$i (not shown), with the NOCP_i distribution remaining close to Gaussian (not shown). The impact of cold pools on the tails of the distributions causes also the minimum temperature to decrease in $\mathrm{CP}_{-} \mathrm{i}$ by as much as $-3 \mathrm{~K}$ (not shown; compared to merely $0.5 \mathrm{~K}$ for the positive part from Fig. 12). The minimum water vapor mixing ratio remains 


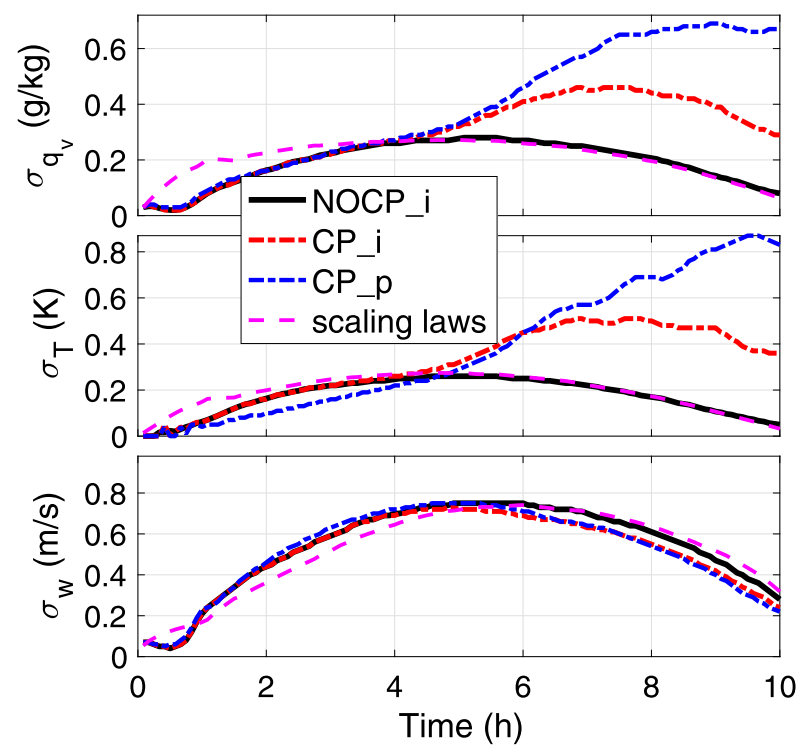

FIG. 8. Time series of the ensemble-averaged standard deviations of the (top) water vapor mixing ratio, (middle) nearsurface temperature, and (bottom) vertical velocity spatial distributions. The evolutions derived from the surface-layer scaling laws are also plotted.

similar with and without cold pools because cold pools act to bring the positive moisture perturbations from above as shown in Fig. 12.

\section{e. Cloud layer and precipitation}

Moving upward from the subcloud layer into the cloud layer, Fig. 13 shows evolutions of the cloud fraction profiles. Cloud fraction is defined as the percentage of grid cells for which the sum of liquid and ice cloud water mixing ratio exceeds $10^{-3} \mathrm{~g} \mathrm{~kg}^{-1}$. During the shallow convection phase, cloud fraction reaches $15 \%$ at the cloud base for both NOCP_i and CP_i, and around $18 \%$ for $\mathrm{CP}_{-} \mathrm{p}$, decreasing with height in the manner typical for shallow cumulus convection (Siebesma et al. 2003). The depth of the cloud layer increases similarly for all three ensembles, with the cloud-top height reaching the freezing level after $3.5 \mathrm{~h}$.

The maximum range of convective plumes for NOCP_i saturates after $5 \mathrm{~h}$ at around $9 \mathrm{~km}$. For $\mathrm{CP}_{-} \mathrm{i}$ and CP_p, the cloud top height keeps increasing until it reaches the tropopause $(\sim 14.5 \mathrm{~km})$ at around $8 \mathrm{~h}$. More moisture transported into the upper troposphere in $\mathrm{CP} \_\mathrm{i}$ and $\mathrm{CP}_{-} \mathrm{p}$ results in a few-percent-smaller cloud fractions in the lower troposphere at later hours compared to NOCP_i. Moreover, $\mathrm{CP} \_$p and $\mathrm{CP} \_\mathrm{i}$ both feature ice anvils around the top of the cloud layer. The height at which the anvil formation is most intense increases with time from $9 \mathrm{~km}$ at $6-7 \mathrm{~h}$ to $12 \mathrm{~km}$ at $8 \mathrm{~h}$ (where it remains for $\mathrm{CP} \_\mathrm{i}$ ) and to $14 \mathrm{~km}$ at $10 \mathrm{~h}$ (for $\mathrm{CP}_{-} \mathrm{p}$ ). The $\mathrm{CP} \_\mathrm{p}$
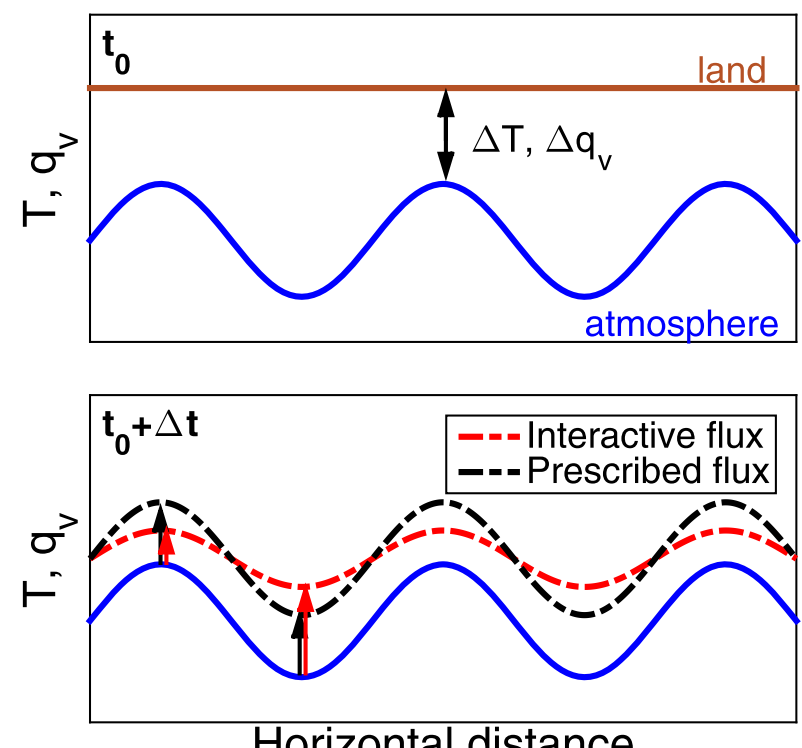

Horizontal distance

FIG. 9. Schematic explanation of the role of interactive fluxes in damping near-surface temperature and/or moisture perturbations. (top) The horizontally uniform surface temperature (or moisture) and the atmospheric temperature (or moisture) perturbations. (bottom) The modified perturbations (dashed lines) due to interactive and prescribed surface fluxes. The prescribed flux simply shifts the pattern without affecting its amplitude. The interactive flux damps the perturbation amplitude.

ensemble features significantly larger transport of moisture into the upper troposphere during the mature phase that results in up to two-times-larger ice cloud fractions than in $\mathrm{CP}_{-} \mathrm{i}$. Although the two $\mathrm{CP}$ simulations are driven by enhanced fluxes, the main factor controlling the deeper cloud-layer development is convection organization. This is because a simulation complementary to $\mathrm{CP}_{-} \mathrm{p}$ but using the prescribed (smaller) fluxes from NOCP_i yields similar results to those for the current $\mathrm{CP} \_\mathrm{p}$ (not shown). Alternatively, a simulation using the enhanced prescribed fluxes, but with the coldpool effects switched off, gives results similar to NOCP_i (not shown). As the surface-driven convection decays toward the end of simulation time, and the low-level cloud fractions decrease to mere $2 \%-3 \%$ for all simulations, the contribution from anvils remains at around $10 \%$ for $\mathrm{CP} \_\mathrm{i}$ and at around $15 \%$ for CP_p. The differences between the three ensembles highlight the role of cold pools in the deep convection forcing (NOCP_i vs $\left.\mathrm{CP} \_\mathrm{i}\right)$ and the role of surface fluxes damping the temperature and moisture perturbations $\left(\mathrm{CP}_{-} \mathrm{i}\right.$ vs $\left.\mathrm{CP} \_\mathrm{p}\right)$.

The above-described differences do not significantly impact the mean liquid water path (LWP; including cloud water only) as it evolves similarly for all three ensembles (see Fig. 14). Notably larger differences (up to a factor of 2) are present for the mean rainwater path 


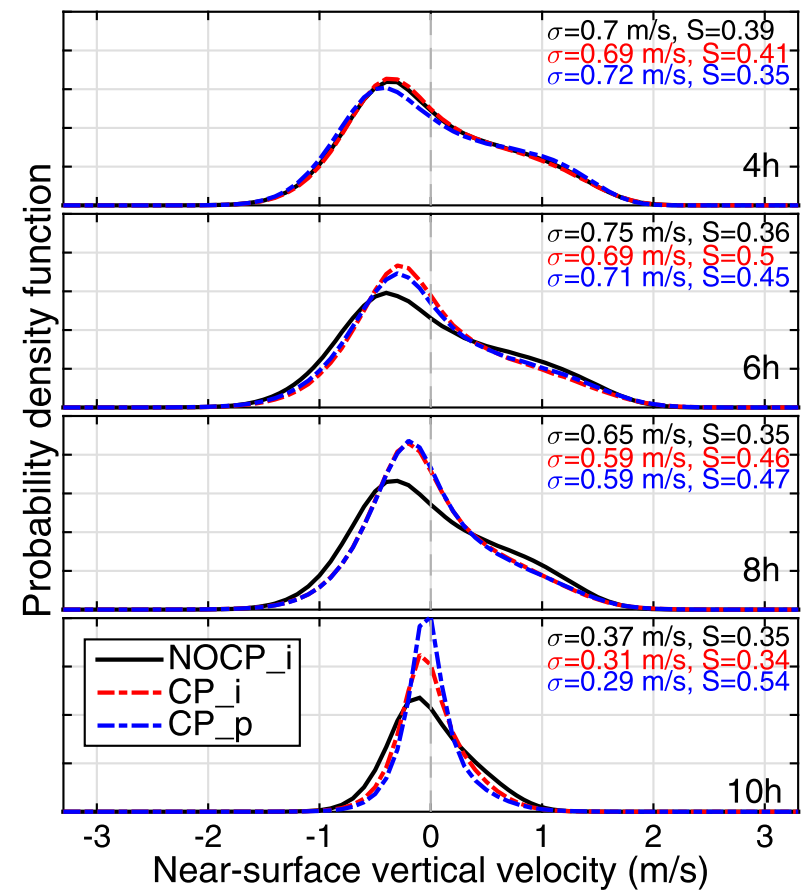

FIG. 10. Probability density distribution of the ensemble-averaged near-surface vertical velocity after (top)-(bottom) 4, 6, 8, and $10 \mathrm{~h}$. The symbols $\sigma$ and $S$ denote, respectively, standard deviation and skewness of the shown distribution.

(RWP) and (up to a factor of 10) for ice water path (IWP; including cloud ice, snow, and graupel). The differences in RWP translate into 2-3 times increased surface precipitation rates and the accumulated precipitations for the $\mathrm{CP}$ simulations, with $\mathrm{CP} \_\mathrm{p}$ featuring the biggest enhancement. Noteworthy, an NOCP simulation using the alternative approach of Khairoutdinov and Randall (2006) to exclude cold-pool effects (i.e., by switching off rain evaporation) yields surface rain rates comparable with those for the CP simulations.

A common factor for all the changes in the cloud fraction, IWP, and RWP, and to a smaller degree the LWP, is the cold-pool induced convection organization (Fig. 2). One of the most prominent effects of cold pools is the clustering of near-surface buoyancy, which helps the updrafts penetrate deeper into the cloud layer (Khairoutdinov and Randall 2006). These updrafts are on average less diluted and develop larger vertical velocities (see next two sections). Consequently, they reach higher altitudes (which increases IWP) and feature larger liquid water mixing ratios within cloud cores (which increases RWP due to larger autoconversion rates). The additional contribution to RWP, mostly for the CP simulations, comes from the graupel formation above the freezing level (not shown). Interestingly, LWP is less affected by the clustering effects because it is proportional to the total
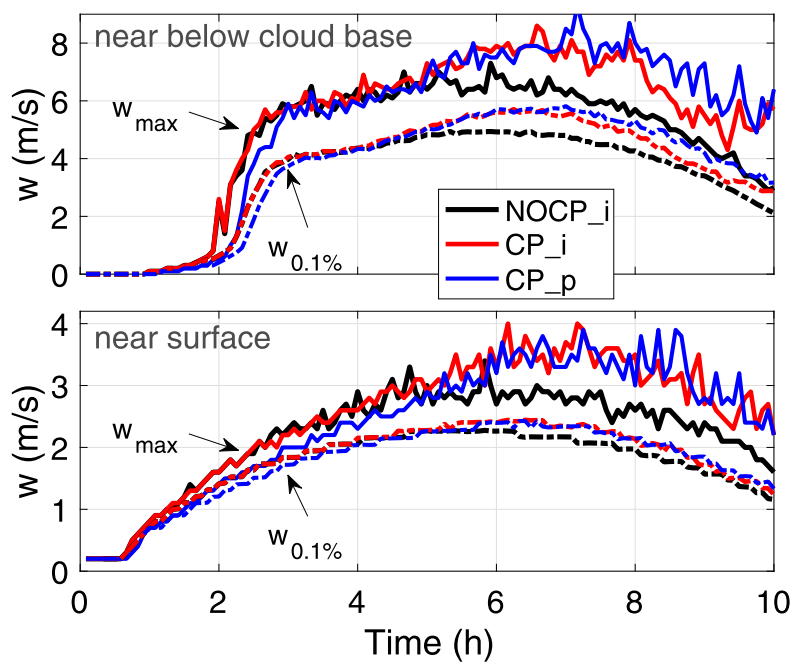

FIG. 11. Time series of vertical velocity (bottom) near the surface $(\sim 100 \mathrm{~m})$ and (top) near below cloud base $(\sim 800 \mathrm{~m})$ for NOCP_i, CP_i, and CP_p ensembles. Maximum values $w_{\max }$ are plotted along with weighted means for $0.1 \%$ of the right tails of the PDFs $w_{0.1 \%}$.

amount of condensed water: While more organized updrafts feature larger maxima of the cloud water, their total updraft area is somewhat decreased.

\section{f. Convective mass flux}

Some insight into the convection organization can be gained by analyzing convective mass flux, which is the key ingredient of many convection parameterizations, including convective plume schemes (Arakawa 2004). The explicitly resolved mass flux within a grid box of an LES model can be calculated as

$$
M_{i j}=a_{i j} \rho_{i j} w_{i j},
$$

where the subscripts $i$ and $j$ specify the horizontal location of a grid box, $\rho$ is air density, $a$ is the updraft area (i.e., horizontal gridbox size), and $w$ is the associated vertical velocity. Since we are primarily interested in the comparison of in-cloud convective mass flux, we constrain the analysis to the cloudy grid points (i.e., containing liquid and/or ice water) with vertical velocity larger than $0.1 \mathrm{~m} \mathrm{~s}^{-1}$. Furthermore, we only analyze the collective transport by cloudy updrafts over the entire domain and its relative change for different ensembles. For this, we calculate mean in-cloud mass flux using the following form:

$$
M_{u}=a_{u} \overline{\rho w}_{u},
$$

where the subscript $u$ denotes the updrafts, $a$ is the normalized total updraft area (between 0 and 1), and the overbar depicts horizontal averaging. In practice, 


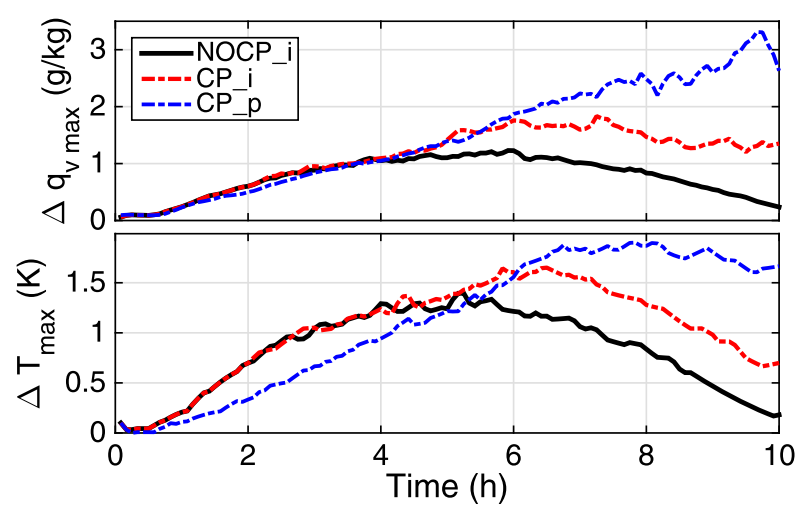

FIG. 12. As in Fig. 11, but for the (top) maximum water vapor mixing ratio and (bottom) temperature perturbations from the surface values at the lowest model level.

horizontal density fluctuations for compressible flows can be neglected without any significant impact on the results (Kurowski et al. 2014). Because condensed water around the cloud base exists mostly in cloud cores, updraft area in that region is almost equivalent to the cloud fraction.

Figure 15 shows evolutions of the updraft area, mean vertical velocity, and their density-weighted product (i.e., the mass flux) for NOCP_i, $\mathrm{CP} \_\mathrm{i}$, and $\mathrm{CP} \_\mathrm{p}$ around the cloud base. In addition to the cloud-base quantities that are most relevant from the parameterization viewpoint, we also plot the results at 4 - and 8 -km heights to contrast the results deeper into the cloud layer.

For the cloud base (left column of Fig. 15), the moist updraft area rapidly increases after the moist convection onset in the second hour and reaches values of $\sim 12 \%$ for NOCP_i and $C P \_i$, and $\sim 15 \%$ for $C_{-} \_$. S Such values are maintained for about $2 \mathrm{~h}$, and then the moist updraft area slowly decreases with time at a similar rate for all ensembles. Differences due to cold pools appear after $6 \mathrm{~h}$, with $\mathrm{CP}_{-} \mathrm{i}$ and $\mathrm{CP} \_$p showing a few-percent-smaller values than NOCP_i. The increase of the mean updraft velocity is steadier, following the evolution of surface fluxes. The impact of cold pools becomes notable an hour earlier for the velocity field than for the updraft area, as the updraft velocity continues to grow after hour 5 in $\mathrm{CP}_{-} \mathrm{i}$ and CP_p. Small differences (around $0.2 \mathrm{~m} \mathrm{~s}^{-1}$ ) between the three ensembles, the smallest for NOCP_i and the largest for $\mathrm{CP}_{-} \mathrm{p}$, persist until the end of the simulations. Because the changes for the two components of the mass flux have opposite signs, the resulting cloud-base mass flux remains very similar for all three ensembles throughout the simulation time. These results suggest that the effects of cold pools have a very limited impact on the cloud-base mass flux, at least in the simulated case. However, the results at higher levels document the increasing-with-height differences between the

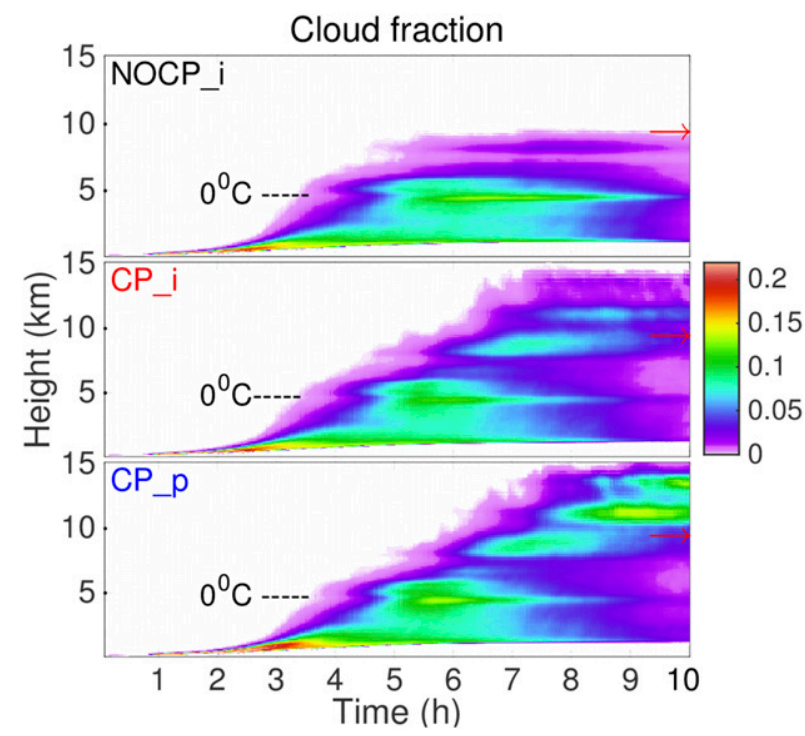

FIG. 13. Evolutions of the ensemble-averaged cloud fraction profiles (with the ice and liquid phases combined) from (top) NOCP_i, (middle) CP_i, and (bottom) CP_p ensembles. Red arrows indicate the vertical range of the NOCP_i ensemble.

ensembles. The differences at $4 \mathrm{~km}$ mostly concern larger mean updraft velocity, with fairly comparable values for the updraft area. The differences among the ensembles are much larger at $8 \mathrm{~km}$, again in agreement with the cloud fraction profiles in Fig. 13.

\section{g. Bulk entrainment rate}

The differences in the mass flux can be understood with a plume model that we use to estimate bulk lateral entrainment as follows (e.g., Siebesma et al. 2003):

$$
\epsilon_{\psi}=-\frac{\partial \psi_{u}}{\partial z}\left(\psi_{u}-\bar{\psi}\right)^{-1}
$$

where $\psi$ is a conserved variable, $u$ relates to the bulk plume properties, and the overbar denotes horizontal averaging. The conserved variable chosen for the analysis is moist static energy (not conserved for the ice phase). The bulk plume properties are calculated as an ensemble mean for the LES updrafts. The calculated profiles of the entrainment rate are almost constant with height below the freezing level, featuring larger values and stronger irregularities above (not shown). To avoid complications with ice, we only analyze the layer with liquid water.

Figure 16 shows evolutions of mean bulk entrainment rates for the three LES ensembles. During the first hour of shallow convection development (i.e., between 2 and $3 \mathrm{~h}$ ), the entrainment rates are the largest as the first few condensing updrafts quickly dissipate. With an increasing number of moist updrafts, convection eventually 


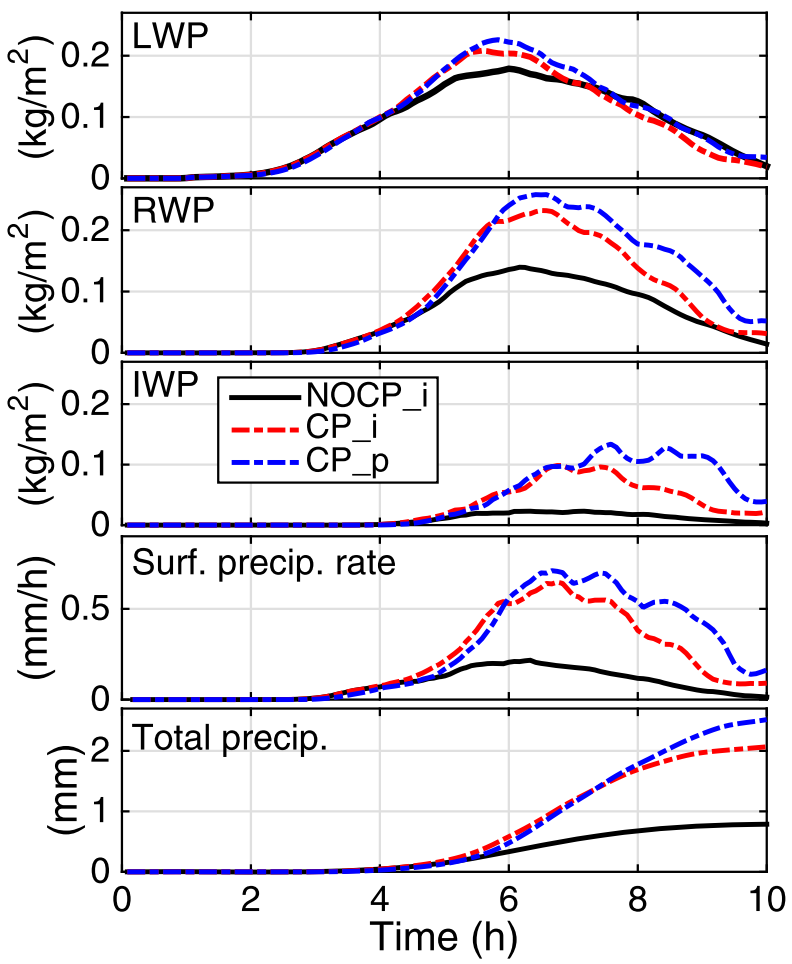

FIG. 14. Time series of the ensemble-averaged (top)-(bottom) LWP, RWP, IWP (including ice, snow, and graupel), surface precipitation rate, and total precipitation for $\mathrm{NOCP}_{-} \mathrm{i}, \mathrm{CP} \mathrm{i}$, and $\mathrm{CP}_{\mathrm{p}} \mathrm{p}$ ensembles.

sets in and the entrainment rates stabilize around $0.9 \times$ $10^{-3} \mathrm{~m}^{-1}$. The NOCP_i rate remains at that level until $6 \mathrm{~h}$ and then steadily increases to $1.2 \times 10^{-3} \mathrm{~m}^{-1}$ at $10 \mathrm{~h}$. This increase is associated with the weakening of surface fluxes and thus of the updrafts themselves. On the contrary, the rates for the $\mathrm{CP}$ simulations begin to decrease after the hour 5, when cold pools start affecting the secondary circulations, and then remain at $0.7-0.8 \times 10^{-3} \mathrm{~m}^{-1}$ for the rest of the day. Note that the differences between the NOCP_i and the CP solutions constantly grow with time, yielding about $30 \%-40 \%$ lower rates for the latter two at $10 \mathrm{~h}$. The bulk entrainment rate decreases more strongly for $\mathrm{CP}_{-} \mathrm{p}$ than for $\mathrm{CP} \_\mathrm{i}$, in agreement with the more intense vertical convection development for prescribed fluxes, as shown before. The fact that bulk entrainment decreases for deep convection is associated with the widening of plumes (i.e., increasing the width of clouds) and/or clustering by cold pools and was reported in many previous studies (e.g., Kuang and Bretherton 2006; Mapes and Neale 2011; Hohenegger and Bretherton 2011; D’Andrea et al. 2014; Glenn and Krueger 2017).

\section{h. Temperature budgets from microphysical heating and cooling}

Another large-scale perspective on cold-pool effects can be gained by calculating the budgets of latent heating due to phase changes of the water substance. Such an analysis is important from a parameterization point of view because physically sound parameterizations should accurately represent not only the net difference between microphysical heat sources and sinks (as encapsulated by the mean surface precipitation) but also the cold-pool-induced differences in the budget of these terms.

For the comparison, we calculate the layer-averaged energy flux $\left(\mathrm{W} \mathrm{m}^{-2}\right)$ as

$$
F_{\text {micro }}=c_{p} \int_{z_{b}}^{z_{t}} \rho\left(\frac{d T}{d t}\right)_{\text {micro }} d z
$$

where $z_{b}$ and $z_{t}$ are the bottom and top heights of the layer. We calculate positive and negative mean energy fluxes separately for the subcloud and cloud layers.
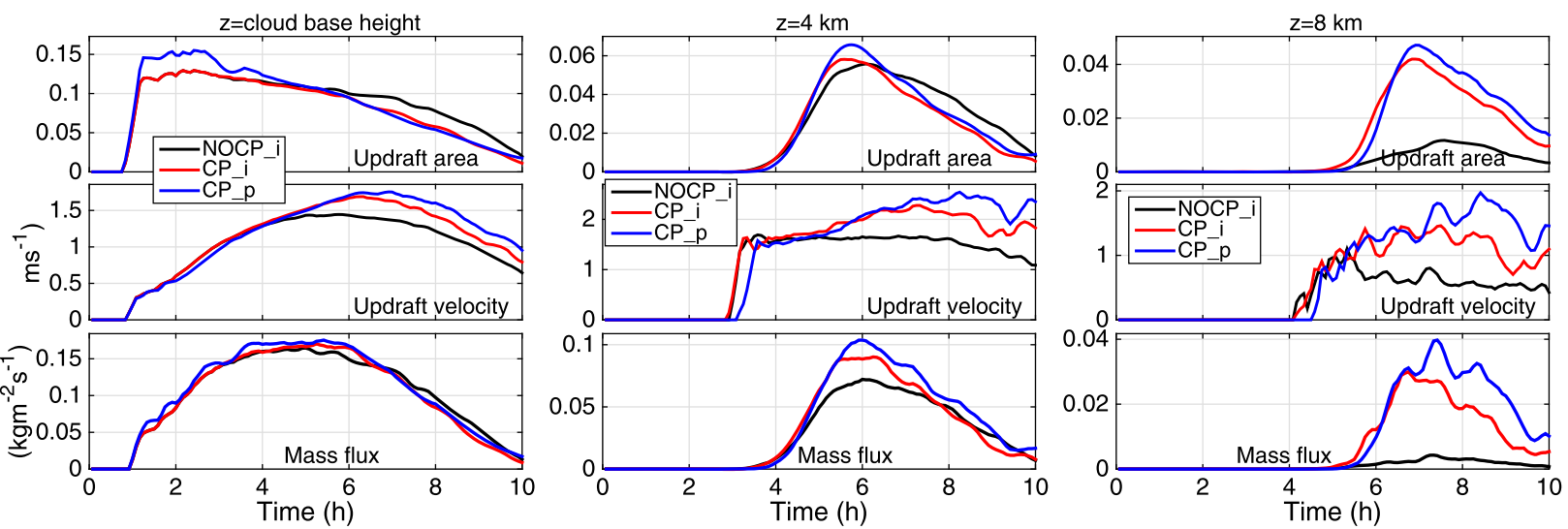

FIG. 15. Time series of the ensemble-averaged (top) updraft area, (middle) mean updraft velocity, and (bottom) the resulting mass flux (left) around the cloud base and at (center) 4 and (right) $8 \mathrm{~km}$ for NOCP_i, CP_i, and CP_p ensembles. The series were smoothed to improve the comparison. 


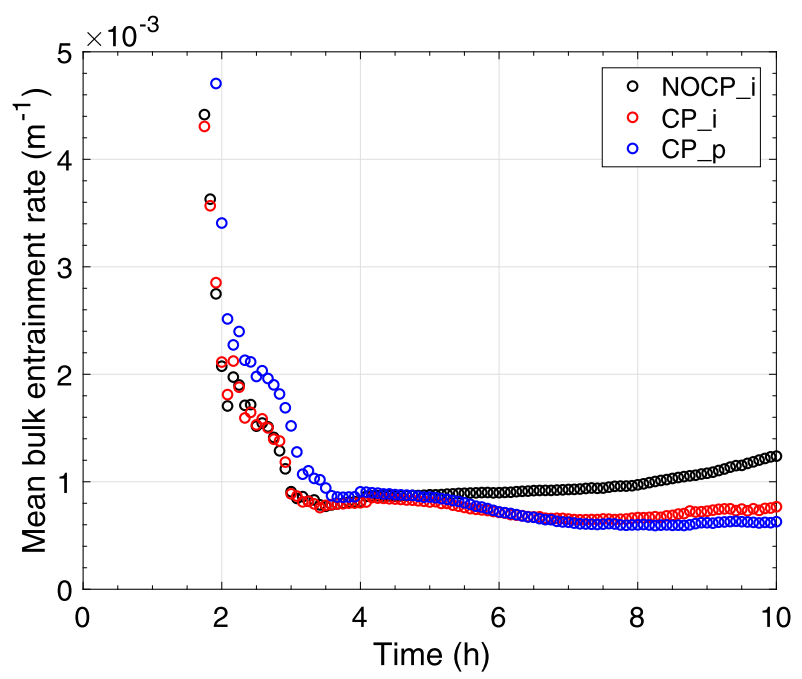

FIG. 16. Time series of the ensemble-averaged bulk entrainment rates below freezing level for $\mathrm{NOCP}_{-} \mathrm{i}, \mathrm{CP} \mathrm{i}$, and $\mathrm{CP} \_\mathrm{p}$ ensembles.

The cloud layer (defined as the layer with nonzero cloud fraction) features both positive and negative contributions, whereas the only contribution in the subcloud layer (defined as the layer from the surface to the cloud base) comes from rain evaporation.

Time series of the energy fluxes due to latent heating and cooling for the two layers are shown in Fig. 17. The negative fluxes from cooling are plotted with the opposite sign to facilitate the comparison with positive fluxes. There are two components for the cloud layer representing the effects of either latent heating (e.g., due to condensation, sublimation, or freezing) or latent cooling (e.g., due to evaporation, resublimation, or melting). Only one component is shown for the subcloud layer as it comes from the rain evaporation. Each of the three components is plotted for $\mathrm{NOCP}_{-} \mathrm{i}, \mathrm{CP}_{-} \mathrm{i}$, and $\mathrm{CP}_{-} \mathrm{p}$. The differences between $\mathrm{CP}_{-} \mathrm{i}$ and $\mathrm{NOCP}_{-} \mathrm{i}$, which quantify the impact of cold pools for interactive fluxes, are shaded red (for cloud-layer heating), blue (for cloudlayer cooling), and black (for subcloud cooling).

Positive energy fluxes first appear above cloud base in the second hour, marking the onset of moist convection. The fluxes in the cloud layer increase strongly as convection deepens between hour 2 and 4 . Positive and negative fluxes are close to each other up to hour 4 as the surface precipitation (i.e., the net warming of the atmosphere) is still small. The two cloud-layer fluxes (i.e., due to heating and cooling) gradually split when significant cloud-layer precipitation develops, with the positive flux significantly exceeding the negative flux. The resulting energy surplus is stored in the condensed water and ice. Some of it falls out of the cloud layer in the form of rain. Before reaching the surface and providing the

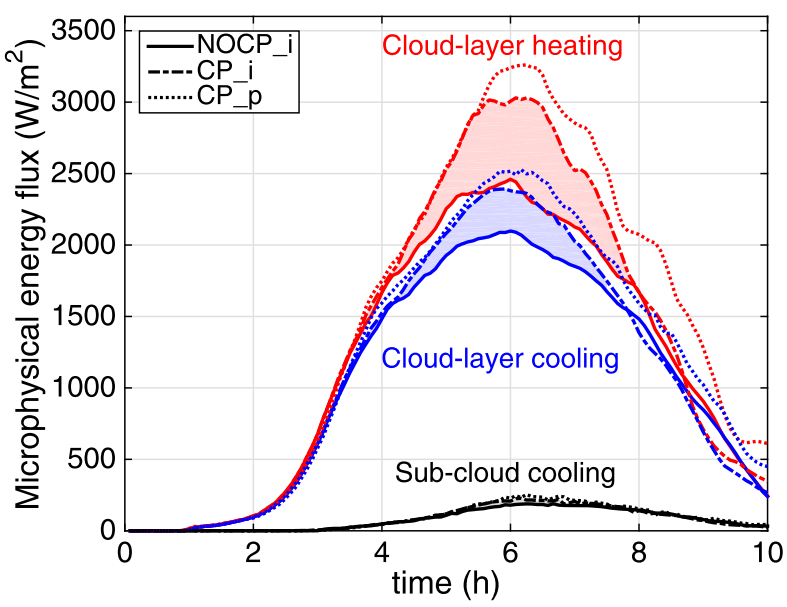

FIG. 17. Time series of the ensemble-averaged mean energy fluxes (absolute values) due to microphysical latent heat release/ absorption below and above the cloud base for NOCP_i, CP_i, and CP_p ensembles. The fluxes above cloud base are split into positive (heating) and negative (cooling) contributions. The fluxes below cloud base are only negative because of rain evaporation. The differences between $\mathrm{CP}_{-} \mathrm{i}$ and $\mathrm{NOCP} \_\mathrm{i}$ are shaded to better expose the cold-pool effects.

net heating of the atmosphere, a fraction of the energy is lost through rain evaporation. Cold pools enhance the negative fluxes in the cloud and subcloud layers by approximately $10 \%-12 \%$. The positive fluxes grow by more than $15 \%$. The enhancement in terms of absolute values $\left(\mathrm{W} \mathrm{m}^{-2}\right)$ is more than 2 times larger for positive than negative fluxes, which is consistent with the enhancement of surface precipitation (cf. Fig. 13) that is the sink term for this budget.

\section{Theoretical considerations}

The results of simulations can also be analyzed on the grounds of Monin-Obukhov similarity theory. The MoninObukhov similarity theory assumes the existence of the universal length scale that relates buoyancy flux to shear,

$$
L=\frac{-\theta_{v s} u_{*}^{3}}{\kappa g\left(\overline{w^{\prime} \theta_{v}^{\prime}}\right)_{s}},
$$

where $\kappa$ is the von Kármán constant, $\theta_{v}$ the virtual potential temperature, subscript $s$ denotes the surface, and

$$
u_{*}=\left[\overline{\left(u^{\prime} w^{\prime}\right)^{2}}+\overline{\left(v^{\prime} w^{\prime}\right)^{2}}\right]^{1 / 4}
$$

is the friction velocity, suitable for describing sheardriven turbulence. Deardorff (1970) showed that for free convection, it is more appropriate to use the convective velocity scale that takes the form (moisture included) as follows: 


$$
w_{*}=\left[\frac{g}{\overline{\theta_{v s}}}\left(\overline{w^{\prime} \theta_{v}^{\prime}}\right)_{s} z_{i}\right]^{1 / 3},
$$

where $z_{i}$ is the depth of the convective layer. Moeng and Sullivan (1994) proposed to merge the velocity scales for the shear- and buoyancy-driven turbulence by introducing a generalized velocity scale,

$$
w_{m}^{3}=w_{*}^{3}+5 u_{*}^{3} .
$$

Using the above, universal temperature and moisture scales can be expressed as the functions of surface fluxes,

$$
\theta_{m}=\frac{\left(\overline{w^{\prime} \theta^{\prime}}\right)_{s}}{w_{m}},
$$

and

$$
q_{m}=\frac{\left(\overline{w^{\prime} q_{v}^{\prime}}\right)_{s}}{w_{m}} .
$$

For horizontally homogeneous and steady-state turbulence, the second moments of vertical velocity and scalars depend on the universal scales and stability functions (Monin and Yaglom 1971; Wyngaard et al. 1971) as follows:

$$
\begin{aligned}
\sigma_{w}^{2} & =w_{m}^{2} \Psi_{w}\left(\frac{z}{L}\right), \\
\sigma_{\theta}^{2} & =\theta_{m}^{2} \Psi_{\theta}\left(\frac{z}{L}\right), \quad \text { and } \\
\sigma_{q}^{2} & =q_{m}^{2} \Psi_{q}\left(\frac{z}{L}\right) .
\end{aligned}
$$

Therefore, the variances can be represented by linear functions of the universal scales at a given stability $z / L$. In particular, the temperature and moisture variances become dependent only on their normalized surface fluxes, while $\Psi_{w}, \Psi_{\theta}$, and $\Psi_{q}$ simplify to constant parameters (cf. Stull 1988),

$$
\begin{aligned}
& \sigma_{w}=w_{m} C_{w}, \\
& \sigma_{\theta}=\theta_{m} C_{\theta}, \quad \text { and } \\
& \sigma_{q}=q_{m} C_{q} .
\end{aligned}
$$

Using these surface-layer scalings to explain our simulation results requires making additional assumptions. For our considerations, we choose $z_{i}$ to be the cloud-base height (i.e., the depth of the well-mixed layer associated with the size of the largest eddies that can feed back on the surface layer) rather than the top of the conditionally unstable cloud layer. The assumption that turbulence is stationary and homogeneous for diurnal convection is quite accurate for NOCP_i; however, it is more questionable for the $\mathrm{CP}$ cases since they are affected by the dynamically evolving cold pools. Note also that the bottom boundary condition for scalars and momentum is simplified, as we use a constant drag coefficient. The Obukhov length decreases in the first $3 \mathrm{~h}$ for NOCP_i and then stabilizes at about -150 to $-170 \mathrm{~m}$ for the next $6 \mathrm{~h}$, while for $\mathrm{CP}$, it keeps decreasing throughout the simulation at approximately a constant rate. Because the resolved vertical velocity vanishes at the lowest model level, $u_{*}$ needs to be calculated at the second level. In our case, $u_{*}$ is 2-3 times smaller than $w_{*}$, which yields $w_{m}$ close to $w_{*}$, indicating the dominant role of buoyancy-driven turbulence.

As shown in Fig. 8, the evolutions of the standard deviations of temperature, moisture, and vertical velocity closely follow the evolutions of normalized surface fluxes for NOCP_i (fitted for $C_{w}=0.34, C_{\theta}=C_{q}=$ 2.55). Noteworthy, they significantly deviate from these scalings, especially for temperature and moisture, when cold pools interact with the surface layer, with the largest differences for prescribed fluxes. The largest disparity for NOCP_i is simulated in the first $3 \mathrm{~h}$, when $z / L$ strongly changes.

Overall, the above considerations indicate that the solution without cold pools preserves basic features of the buoyancy-driven quasi-steady convection. As such, it can be considered a starting point for the existing shallow convection parameterizations aiming at the extension of their framework to include deep convection. It is worth mentioning that similar scaling laws have been used to describe the variability of near-surface conditions for multiple convective updrafts in shallow convection parameterizations (Cheinet 2003; K. Sušelj et al. 2018, unpublished manuscript).

\section{Summary and conclusions}

The present study uses a robust method to extract and quantify the impact of cold pools and interactive surface heat fluxes on shallow-to-deep convection transition over land in a large-eddy simulation (LES). Therefore, it extends the works of Grabowski et al. (2006) and Khairoutdinov and Randall (2006), which instead prescribe diurnal evolution of the fluxes, while providing a simple and efficient methodology to evaluate these effects both for steady-state and time-dependent scenarios. The computational framework is based on three different configurations of the LES model. The first ensemble (referred to as NOCP_i) uses interactive fluxes and excludes cold pools by horizontally 
homogenizing the temperature and moisture tendencies due to rain evaporation, as in Böing et al. (2012). The applied modification mimics the approach of onedimensional convection parameterizations and helps obtain a novel reference solution useful in their development. The second ensemble $\left(\mathrm{CP} \_\mathrm{i}\right)$ includes the effects of cold pools for interactive fluxes driven by the diurnal cycle of the spatially uniform land surface temperature and moisture conditions. This is arguably the simplest methodology that allows an extension of the prescribed surface fluxes approach of Grabowski et al. (2006) and Khairoutdinov and Randall (2006) to the interactive surface fluxes simulation. The third ensemble (CP_p) includes the effects of cold pools for prescribed fluxes derived from $\mathrm{CP} \_\mathrm{i}$ to quantify the role of land surface interactions in the development of deep convection. As cold pools develop, their direct effects (on the subcloud layer) and indirect effects (on the cloud layer through secondary circulations) are analyzed.

One of the most apparent direct impacts of cold pools is the enhancement of mean surface latent and sensible heat fluxes. The enhancement is driven mostly by the associated wind bursts as shown by additional analysis and sensitivity simulations. As a result, daily flux maxima in $\mathrm{CP}_{-} \mathrm{i}$ are delayed by about an hour when compared to the NOCP_i ensemble. The time-averaged enhancement $\left(\mathrm{Wm}^{-2}\right)$ is approximately the same for sensible and latent heat fluxes. As one might expect, the near-surface standard deviations of air temperature and moisture spatial distributions are significantly larger when cold pools are present, while the near-surface vertical velocity standard deviation is only weakly affected (cf. Fig. 8). The distributions of the near-surface properties are important for convection schemes based on a plume model as they can determine initial conditions for the plume integration. Although the mean and standard deviation of the near-surface vertical velocity are relatively weakly affected by the presence of cold pools, the maximum vertical velocities near the surface and especially at the cloud base increase significantly when cold pools are present (cf. Fig. 11). The latter indicates that the enhancement is due to mechanical forcing from the wind convergence, but also due to the buoyancy accumulation near the surface.

The indirect impact of cold pools is more difficult to interpret because of the existing feedback between coldpool strength and rain formation. However, cold pools are found to strongly increase the convective heating rates in the cloud layer, while only slightly modifying the cloud-base convective mass flux. They also reduce the bulk entrainment rate aloft by up to $30 \%-40 \%$, arguably because of convection organization. This translates into a few-kilometer-deeper cloud layer with cold pools, and notably increases the mean condensed water paths and the surface precipitation (cf. Fig. 14). In particular, accumulated surface precipitation after $10 \mathrm{~h}$ is between 2 and 3 times larger in $\mathrm{CP}_{-} \mathrm{i}$ and $\mathrm{CP}_{-} \mathrm{p}$ than in NOCP_i. Moreover, CP_p has larger values of the uppertropospheric cloud fractions, rain, and ice water paths, as well as surface rain accumulations than $\mathrm{CP}_{-} \mathrm{i}$. It also features larger near-surface temperature of moisture maxima and standard deviations of their spatial distributions. We argue that all these come from the damping mechanism associated with the interactive surface fluxes as schematically explained in the description of Fig. 9.

The new reference solution without cold pools is examined and shown to preserve many features of dry and/ or shallow cellular convection, including the surface-layer scaling laws for the variances of temperature, moisture, and vertical velocity. This is an important new result indicating (perhaps not surprisingly) that deep convection can be seen as a more intense shallow or even dry convection when cold pools are eliminated. It follows that the extension of shallow convection parameterizations to deep convection should merely include the effects of cold pools, with some of them quantified in this study.

The simulated cold pools in the LBA case are relatively weak because the tropical environment is quite humid. The latter limits the negative buoyancy production due to rain evaporation. Stronger cold pools and larger enhancement of surface fluxes as well as cold-pool wind gusts are expected for drier environments, for instance, those associated with midlatitude deep convective systems. The uncertainty due to different land types does not seem significant, at least for the simple bulk aerodynamic flux formulation and constant drag coefficients ranging between 0.012 and 0.030 . However, there is a significant uncertainty due to the impact of cloud microphysics parameterization (see also Grabowski 2015). Several tested microphysical schemes produced different partitioning among the cloud water species and the differences in the surface precipitation rates and significant differences in the rain accumulations. Such uncertainties make the challenges facing single-column models, and convection parameterization in general, even more difficult.

Acknowledgments. The research was carried out at the Jet Propulsion Laboratory, California Institute of Technology, under a contract with the National Aeronautics and Space Administration. Part of this research was supported by the U.S. Department of Energy, Office of Biological and Environmental Research, Earth System Modeling. We also acknowledge the support provided by the NASA MAP Program and the NOAA/ CPO MAPP Program. This work was partially supported by the U.S. DOE ASR Grant DE-SC0016476. 


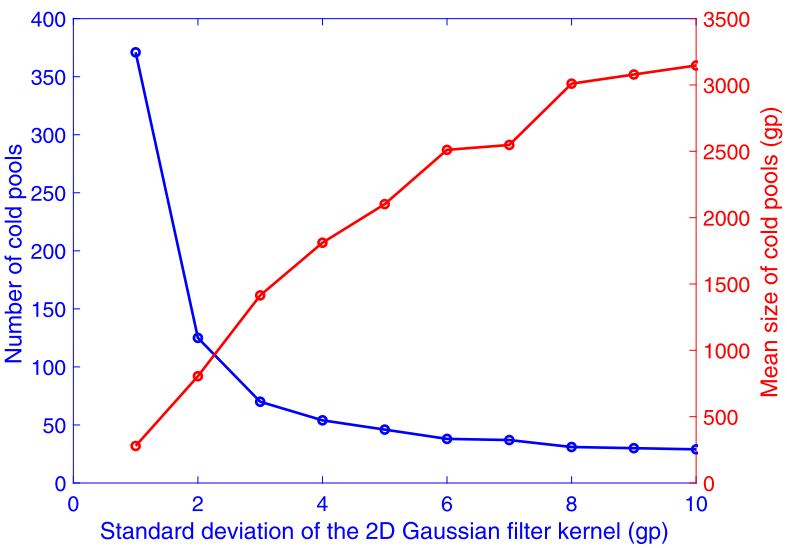

FIG. A1. Number of identified cold pools and their mean size as a function of standard deviation of the 2D Gaussian kernel filter (in grid points) applied to the virtual potential temperature field at the lowest model level calculated for a random $\mathrm{CP}$ i ensemble member at $8 \mathrm{~h}$.

Support from Emily Serman in editing the manuscript is acknowledged. Comments and suggestions from the three anonymous reviewers are greatly appreciated.

\section{APPENDIX}

\section{Cold-Pool Identification Algorithm}

The cold-pool identification algorithm used in the study is based on the virtual potential temperature perturbations analyzed at the lowest model level. Since cold pools are associated with descending density currents driven by rain evaporation, they are considered as near-surface regions of increased density (i.e., of decreased virtual potential temperature). For the analyzed case, in which cold pools are relatively weak, the threshold is set to $-0.35 \mathrm{~K}$, which is around one (negative) standard deviation of the near-surface virtual potential temperature. To avoid problems associated with the presence of small-scale features in LES, which can lead to a significant underestimation of the sizes of larger cold pools (often seen as clusters of smaller pools), the buoyancy field is filtered using the twodimensional Gaussian filter, with the 600-m standard deviation of the filter kernel (Fig. A1). This value is close to the typical size of convective cells, for which the number of identified cold pools is almost independent of the filter scale, while the mean cold-pool area changes much less significantly than for the smaller values.

\section{REFERENCES}

Arakawa, A., 2004: The cumulus parameterization problem: Past, present, and future. J. Climate, 17, 2493-2525, https://doi.org/ 10.1175/1520-0442(2004)017<2493:RATCPP >2.0.CO;2.
Böing, S. J., H. J. J. Jonker, A. P. Siebesma, and W. W. Grabowski, 2012: Influence of the subcloud layer on the development of a deep convective ensemble. J. Atmos. Sci., 69, 2682-2698, https://doi.org/10.1175/JAS-D-11-0317.1.

Byers, H. R., and R. R. Braham Jr., 1949: The Thunderstorm. U.S. Government Printing Office, $287 \mathrm{pp}$.

Cheinet, S., 2003: A multiple mass-flux parameterization for the surface-generated convection. Part I: Dry plumes. J. Atmos. Sci., 60, 2313-2327, https://doi.org/10.1175/1520-0469(2003) 060<2313:AMMPFT > 2.0.CO;2.

_ 2004: A multiple mass flux parameterization for the surfacegenerated convection. Part II: Cloudy cores. J. Atmos. Sci., 61, 1093-1113, https://doi.org/10.1175/1520-0469(2004)061<1093: AMMFPF $>2.0 . \mathrm{CO} ; 2$.

Cotton, W. R., G. H. Bryan, and S. C. van den Heever, 2011: Storm and Cloud Dynamics. 2nd ed. Academic Press, 809 pp.

D'Andrea, F., P. Gentine, A. K. Betts, and B. R. Lintner, 2014: Triggering deep convection with a probabilistic plume model. J. Atmos. Sci., 71, 3881-3901, https://doi.org/10.1175/JAS-D13-0340.1.

Deardorff, J. W., 1970: Convective velocity and temperature scales for the unstable planetary boundary layer and for Rayleigh convection. J. Atmos. Sci., 27, 1211-1213, https://doi.org/ 10.1175/1520-0469(1970)027<1211:CVATSF $>2.0 . C O ; 2$.

Del Genio, A. D., J. Wu, and Y. Chen, 2012: Characteristics of mesoscale organization in WRF simulations of convection during TWP-ICE. J. Climate, 25, 5666-5688, https://doi.org/ 10.1175/JCLI-D-11-00422.1.

Drager, A. J., and S. C. van den Heever, 2017: Characterizing convective cold pools. J. Adv. Model. Earth Syst., 9, 10911115, https://doi.org/10.1002/2016MS000788.

Feng, Z., S. Hagos, A. K. Rowe, C. D. Burleyson, M. N. Martini, and S. P. de Szoeke, 2015: Mechanisms of convective cloud organization by cold pools over tropical warm ocean during the AMIE/DYNAMO field campaign. J. Adv. Model. Earth Syst., 7, 357-381, https://doi.org/10.1002/2014MS000384.

Gentine, P., A. Garelli, S.-B. Park, J. Nie, G. Torri, and Z. Kuang, 2016: Role of surface heat fluxes underneath cold pools. Geophys. Res. Lett., 43, 874-883, https://doi.org/10.1002/2015GL067262.

Glenn, I. B., and S. K. Krueger, 2017: Connections matter: Updraft merging in organized tropical deep convection. Geophys. Res. Lett., 44, 7087-7094, https://doi.org/10.1002/2017GL074162.

Grabowski, W. W., 2015: Untangling microphysical impacts on deep convection applying a novel modeling methodology. J. Atmos. Sci., 72, 2446-2464, https://doi.org/10.1175/JAS-D14-0307.1.

— , and Coauthors, 2006: Daytime convective development over land: A model intercomparison based on LBA observations. Quart. J. Roy. Meteor. Soc., 132, 317-344, https://doi.org/ 10.1256/qj.04.147.

Grandpeix, J.-Y., J.-P. Lafore, and F. Cheruy, 2010: A density current parameterization coupled with Emanuel's convection scheme. Part II: 1D simulations. J. Atmos. Sci., 67, 898-922, https://doi.org/10.1175/2009JAS3045.1.

Grant, L. D., and S. C. van den Heever, 2016: Cold pool dissipation. J. Geophys. Res. Atmos., 121, 1138-1155, https://doi.org/10.1002/ 2015JD023813.

Guichard, F., and Coauthors, 2004: Modelling the diurnal cycle of deep precipitating convection over land with cloud-resolving models and single-column models. Quart. J. Roy. Meteor. Soc., 130, 3139-3172, https://doi.org/10.1256/qj.03.145.

Hohenegger, K., and C. S. Bretherton, 2011: Simulating deep convection with a shallow convection scheme. Atmos. Chem. 
Phys., 11, $10389-10$ 406, https://doi.org/10.5194/acp-11-103892011.

Houze, R. A., Jr., and A. K. Betts, 1981: Convection in GATE. Rev. Geophys., 19, 541-576, https://doi.org/10.1029/ RG019i004p00541.

Khairoutdinov, M., and D. Randall, 2006: High-resolution simulation of shallow-to-deep convection transition over land. J. Atmos. Sci., 63, 3421-3436, https://doi.org/10.1175/JAS3810.1.

Kuang, Z., and C. S. Bretherton, 2006: A mass-flux scheme view of a high-resolution simulation of a transition from shallow to deep cumulus convection. J. Atmos. Sci., 63, 1895-1909, https:// doi.org/10.1175/JAS3723.1.

Kurowski, M. J., W. W. Grabowski, and P. K. Smolarkiewicz, 2014: Anelastic and compressible simulation of moist deep convection. J. Atmos. Sci., 71, 3767-3787, https://doi.org/10.1175/ JAS-D-14-0017.1.

Lin, Y.-L., R. D. Farley, and H. D. Orville, 1983: Bulk parameterization of the snow field in a cloud model. J. Climate Appl. Meteor., 22, 1065-1092, https://doi.org/10.1175/1520-0450(1983) 022<1065:BPOTSF $>2.0 . \mathrm{CO} ; 2$.

Mahrt, L., D. Vickers, J. Sun, N. O. Jensen, H. Jørgensen, E. Pardygak, and H. Fernando, 2001: Determination of the surface drag coefficient. Bound.-Layer Meteor., 99, 249-276, https://doi.org/10.1023/A:1018915228170.

Mapes, B., and R. Neale, 2011: Parameterizing convective organization to escape the entrainment dilemma. J. $A d v$. Model. Earth Syst., 3, M06004, https://doi.org/10.1029/ 2011MS000042.

Mason, P. J., 1989: Large-eddy simulation of the convective atmospheric boundary layer. J. Atmos. Sci., 46, 1492-1516, https://doi.org/10.1175/ 1520-0469(1989)046<1492:LESOTC > 2.0.CO;2.

Moeng, C.-H., and P. P. Sullivan, 1994: A comparison of shear- and buoyancy-driven planetary boundary layer flows. J. Atmos. Sci., 51, 999-1022, https://doi.org/10.1175/1520-0469(1994) $051<0999: A C O S A B>2.0 . C O ; 2$.

Monin, A. S., and A. M. Yaglom, 1971: Statistical Fluid Mechanics. MIT Press, 769 pp.

Neggers, R. A. J., 2009: A dual mass flux framework for boundary layer convection. Part II: Clouds. J. Atmos. Sci., 66, 1489-1506, https://doi.org/10.1175/2008JAS2636.1.

Nie, J., and Z. Kuang, 2012: Responses of shallow cumulus convection to large-scale temperature and moisture perturbations: A comparison of large-eddy simulations and a convective parameterization based on stochastically entraining parcels. J. Atmos. Sci., 69, 1936-1956, https://doi.org/ 10.1175/JAS-D-11-0279.1.

Redelsperger, J.-L., F. Guichard, and S. Mondon, 2000: A parameterization of mesoscale enhancement of surface fluxes for large-scale models. J. Climate, 13, 402-421, https://doi.org/ 10.1175/1520-0442(2000)013<0402:APOMEO>2.0.CO;2.

Rio, C., F. Hourdin, J.-Y. Grandpeix, and J.-P. Lafore, 2009: Shifting the diurnal cycle of parameterized deep convection over land. Geophys. Res. Lett., 36, L07809, https://doi.org/ 10.1029/2008GL036779.
Rotunno, R., J. B. Klemp, and M. L. Weisman, 1988: A theory for strong, long-lived squall lines. J. Atmos. Sci., 45, 463-485, https:// doi.org/10.1175/1520-0469(1988)045<0463:ATFSLL>2.0.CO;2.

Schlemmer, L., and C. Hohenegger, 2014: The formation of wider and deeper clouds as a result of cold-pool dynamics. J. Atmos. Sci., 71, 2842-2858, https://doi.org/10.1175/JAS-D-13-0170.1.

Siebesma, A. P., and Coauthors, 2003: A large eddy simulation intercomparison study of shallow cumulus convection. J. Atmos. Sci., 60, 1201-1219, https://doi.org/10.1175/15200469(2003)60<1201:ALESIS>2.0.CO;2.

Skamarock, W. C., and Coauthors, 2008: A description of the Advanced Research WRF version 3. NCAR Tech. Note NCAR/ TN-475+STR, 113 pp., https://doi.org/10.5065/D68S4MVH.

Stull, R. B., 1988: An Introduction to Boundary Layer Meteorology. Kluwer Academic, 666 pp.

Sušelj, K., J. Teixeira, and G. Matheou, 2012: Eddy diffusivity/mass flux and shallow cumulus boundary layer: An updraft PDF multiple mass flux scheme. J. Atmos. Sci., 69, 1513-1533, https://doi.org/10.1175/JAS-D-11-090.1.

,-- , and D. Chung, 2013: A unified model for moist convective boundary layers based on a stochastic eddy-diffusivity/ mass-flux parameterization. J. Atmos. Sci., 70, 1929-1953, https:// doi.org/10.1175/JAS-D-12-0106.1.

Teixeira, J., and Coauthors, 2008: Parameterization of the atmospheric boundary layer: A view from just above the inversion. Bull. Amer. Meteor. Soc., 89, 453-458, https://doi.org/10.1175/ BAMS-89-4-453.

Thomas, L., N. Malap, W. W. Grabowski, K. Dani, and T. V. Prabha, 2018: Convective environment in pre-monsoon and monsoon conditions over the Indian subcontinent: The impact of surface forcing. Atmos. Chem. Phys., 18, 7473-7488, https:// doi.org/10.5194/acp-18-7473-2018.

Tompkins, A. M., 2001: Organization of tropical convection in low vertical wind shears: The role of cold pools. J. Atmos. Sci., 58, 1650-1672, https://doi.org/10.1175/1520-0469(2001)058<1650: OOTCIL>2.0.CO;2.

Torri, G., Z. Kuang, and Y. Tian, 2015: Mechanisms for convection triggering by cold pools. Geophys. Res. Lett., 42, 1943-1950, https://doi.org/10.1002/2015GL063227.

Trier, S. B., W. C. Skamarock, and M. A. LeMone, 1997: Structure and evolution of the 22 February 1993 TOGA COARE squall line: Organization mechanisms inferred from numerical simulation. J. Atmos. Sci., 54, 386-407, https://doi.org/10.1175/ 1520-0469(1997)054<0386:SAEOTF>2.0.CO;2.

van Heerwaarden, C. C., and J. P. Mellado, 2016: Growth and decay of a convective boundary layer over a surface with a constant temperature. J. Atmos. Sci., 73, 2165-2177, https:// doi.org/10.1175/JAS-D-15-0315.1.

Wallace, J. M., and P. V. Hobbs, 2006: Atmospheric Science: An Introductory Survey. Academic Press, 504 pp.

Wyngaard, J. C., O. R. Coté, and Y. Izumi, 1971: Local free convection, similarity, and the budgets of shear stress and heat flux. J. Atmos. Sci., 28, 1171-1182, https://doi.org/10.1175/ 1520-0469(1971)028<1171:LFCSAT>2.0.CO;2. 